\title{
Quantitative Expression of Hepatobiliary Transporters and Functional Uptake of Substrates in Hepatic Two-Dimensional Sandwich Cultures: A Comparative Evaluation of Upcyte and Primary Human Hepatocytes ${ }^{\text {柿 }}$
}

\author{
Michelle Schaefer, ${ }^{1}$ Gaku Morinaga, Akiko Matsui, Gerhard Schänzle, Daniel Bischoff, \\ and Roderich D. Süssmuth
}

Department of Drug Discovery Sciences, Boehringer Ingelheim Pharma GmbH \& Co. KG, Biberach an der Riss, Germany (M.S., G.S., D.B.); Department of Pharmacokinetics and Nonclinical Safety, Kobe Pharma Research Institute, Nippon Boehringer Ingelheim Co. Ltd., Kobe, Japan (G.M., A.M.); and Institut für Chemie, Technische Universität Berlin, Berlin, Germany (R.D.S.)

Received August 24, 2017; accepted November 27, 2017

\section{ABSTRACT}

Deficient functional expression of drug transporters incapacitates most hepatic cell lines as a reliable tool for evaluating transportermediated drug-drug interactions. Recently, genetically modified cells (referred to as upcyte hepatocytes) have emerged as an expandable, noncancerous source of human hepatic cells. Herein, we quantified mRNA and protein levels of key hepatobiliary transporters and we assessed associated uptake activity in short- and long-term cultures of upcyte human hepatocytes (UHH) in comparison to cryopreserved primary human hepatocytes (cPHH). Expression of canalicular efflux pumps, such as MRD1/ABCB1, MATE1/SLC47A1, and MRP2/ABCC2, was relatively well preserved in UHH. By contrast, long-term cultivation of UHH in a two-dimensional sandwich configuration [sandwich-cultured upcyte human hepatocytes (SCUHH)] was required to upregulate organic anion-transporting polypeptide OATP1B1/SLCO1B1, OATP2B1/SLCO2B1, NTCP/SLC10A1, and OCT1/SLC22A1 mRNA expression, which correlated well with respective protein abundances. However, mRNA and protein levels of sinusoidal solute carrier transporters, except for NTCP and OATP2B1, remained low in SCUHH compared to sandwich-cultured cPHH. OCT1- and NTCP-mediated uptake of $\mathrm{N}$-methyl-4-phenylpyridinium acetate and taurocholate was demonstrated in both hepatic models, whereas active uptake of OATP1B1/1B3-selective marker substrates, paralleled by markedly reduced SLCO1B1/1B3 expression, were not detectable in SCUHH. Uptake studies under $\mathrm{Na}^{+}$-depletion and excess of taurocholate confirmed the presence of functional NTCP protein and indicated that NTCP, apart from OATP2B1, contributed substantially to the overall hepatic uptake of rosuvastatin in SCUHH. In conclusion, our data suggest that SCUHH, despite their limitation for evaluating OATP1B1/1B3-mediated transport processes, retain NTCP, OATP2B1, and OCT1 transport activities and thus may be considered as a tool for elucidating compensatory uptake pathways for OATP1B1/1B3 substrates.
Introduction

Pharmacokinetics and target tissue exposure of xenobiotics are determined actively by basolateral uptake and efflux processes,

This work was supported by Boehringer Ingelheim Pharma GmbH \& Co. KG.

${ }^{1}$ Current affiliation: Department of Quantitative Pharmacology and Disposition, Merck KGaA, Darmstadt, Germany.

https://doi.org/10.1124/dmd.117.078238.

S This article has supplemental material available at dmd.aspetjournals.org. metabolism, and biliary and renal excretion. Major involvement of hepatic transporters in the net hepatic clearance (CL) of a drug also implies susceptibility for drug-drug interactions (DDIs) and the risk for undesired side effects (Liu and Sahi, 2016). Thus, regulatory agencies advise to critically evaluate the likelihood of an interaction between investigational new molecular entities and drug transporters during early drug development (Patel et al., 2016).

The use of fresh or cryopreserved primary human hepatocytes (cPHH) as a holistic preclinical model is clearly the most appropriate choice for studying hepatobiliary clearance of new molecular entities (Ménochet

ABBREVIATIONS: 2D, two-dimensional; ABC, ATP binding cassette; BCRP, breast cancer resistance protein; BSEP, bile salt export pump; CL, clearance; $\mathrm{cPHH}$, cryopreserved primary human hepatocytes; CV, coefficient of variance; DDI, drug-drug interaction; $\gamma$-GTP, $\gamma$-glutamyl transpeptidase; IS, internal standard; LC, liquid chromatography; LOQ, limit of quantification; MATE, multidrug and toxin extrusion protein; MDR, multidrug resistance protein; MPEX-PTS, Membrane Protein Extraction phase-transfer surfactant; $\mathrm{MPP}^{+}, \mathrm{N}$-methyl-4-phenylpyridinium acetate; MRM, multiple reaction monitoring; MRP, multidrug resistance-associated protein; NTCP, $\mathrm{Na}^{+}$-taurocholate cotransporting polypeptide; OATP, organic anion-transporting polypeptide; OCT, organic cation transporter; OSM, oncostatin M; P450, cytochrome $\mathrm{P} 450$; $\mathrm{PHH}$, primary human hepatocyte; QC, quality control; qRT-PCR, quantitative real-time polymerase chain reaction; RIV SV, rifamycin SV; SCHH, sandwich-cultured human hepatocytes; SCUHH, sandwich-cultured upcyte human hepatocytes; SIL, stable isotope-labeled; SLC, solute carrier; SRM, selected reaction monitoring; UHH, upcyte human hepatocytes; WME, Williams' E medium. 
et al., 2012; Yoshida et al., 2013). Despite being commercially available, the broad phenotypic variability in cytochrome P450 (P450)/UDPglucuronosyltransferase and/or drug transporter expression and activity often requires a costly and time-consuming precharacterization of different hepatocyte batches. Ultimately, the ones identified as appropriate will be limited in the number of cells available. Against this backdrop, in vitro models building on proliferating hepatic cells of human cancerous or noncancerous origin, provided that hepatic physiology is well reflected, would certainly be of interest for drug metabolism and pharmacokinetics screening cascades. In this respect, differentiated HepaRG cells have been proposed as a surrogate for $\mathrm{cPHH}$. In contrast with other hepatoma cell lines such as HepG2 or Huh-7 (Le Vee et al., 2006; Guo et al., 2011; Jouan et al., 2016), mRNA and protein expression of important transporters of the solute carrier (SLC) and ATP binding cassette (ABC) family, as well as associated uptake of typical marker substrates, has been demonstrated for the HepaRG cell line (Kotani et al., 2012; Le Vee et al., 2013). Certainly, particular consideration must be given to the fact that HepaRG cells, as a mixed population of hepatocyte-like and biliary epithelial-like cells (Aninat et al., 2006), only represent the phenotype of one single donor.

A method including transduction of lentiviral constructs carrying human papilloma virus oncogenes was described recently (Levy et al., 2015 ), by which the proliferative capability of primary human hepatocytes (PHH) can be transiently induced via oncostatin M (OSM). This novel upcyte technique, theoretically applicable to any desired hepatocyte donor, led to the introduction of second-generation cryopreserved upcyte human hepatocytes (UHH), available at a virtually unlimited quantity per donor. Unlike HepG2, differentiated UHH exhibit key attributes of mature hepatic cells [including functional aryl hydrocarbon receptor-, constitutive androstane receptor-, and pregnane X receptormediated P450 regulation (Ramachandran et al., 2015); functional epithelial polarization and bile flow (Levy et al., 2015); and ureogenesis and albumin synthesis (Tolosa et al., 2016)], supporting their usefulness as a screening in vitro tool for DDIs and hepatotoxicity assessment (Ramachandran et al., 2015; Tolosa et al., 2016). In addition, we reported recently on the $\mathrm{P} 450$-, uridine 5 '-diphospho-glucuronosyltransferase-, and sulfotransferase-mediated metabolic capability of cultured UHH and demonstrated their utility as a hepatic model for intrinsic clearance determinations of slowly metabolized drugs (Schaefer et al., 2016). Despite this broad characterization of UHH, only limited data on the expression of drug transporters, in particular for clinically relevant hepatic transporters including organic aniontransporting polypeptide OATP1B1/1B3 (encoded by SLCO1B1/1B3), are currently available. Compared with HepG2 cells, considerably higher mRNA expression of $\mathrm{Na}^{+}$-taurocholate cotransporting polypeptide (NTCP/SLC10A1) was observed in differentiated UHH (Tolosa et al., 2016), coinciding with the report by Levy et al. (2015) for NTCP, organic cation transporter 1 (OCT1/SLC22A1), multidrug resistance protein 1 (MDR1/ABCB1), and the bile salt export pump (BSEP/ $A B C B 11)$. Although these results indicate the preservation of selected uptake and efflux transporters in $\mathrm{UHH}$, data on functional activity have not yet been reported.

This study was designed to address questions regarding the applicability of UHH for xenobiotic-transport studies and their potential use for evaluating synergistic intrinsic CL processes. To this end, we analyzed the expression of pharmacokinetic- and DDI-relevant sinusoidal uptake and canalicular efflux transporters using plated UHH derived from three different donors in conjunction with cultivation-duration; finally, we assessed the associated uptake activity of OATPs, NTCP, and OCT1. $\mathrm{cPHH}$ from three donors served as reference. To our knowledge, this is the first comprehensive report describing the abundance of drug transporters in long-term sandwich cultures of UHH at the gene, protein, and functional levels, compared with sandwich-cultured human hepatocytes (SCHH).

\section{Materials and Methods}

Chemicals and Reagents. Calcium chloride, choline chloride, D-glucose solution (10\%), dexamethasone, dimethylsulfoxide, estradiol-17 $\beta$-glucuronide $\left(\mathrm{E}_{2} 17 \beta \mathrm{G}\right)$, HEPES solution, hydrochloric acid solution (1 N, cell culture tested), magnesium sulfate, $\mathrm{N}$-methyl-4-phenylpyridinium acetate $\left(\mathrm{MPP}^{+}\right)$, penicillinstreptomycin $(100 \times)$, potassium bicarbonate, potassium chloride solution (75 mM), potassium phosphate monobasic, pravastatin, rifamycin SV (RIF SV) sodium salt, sodium chloride, sodium bicarbonate solution $(7.5 \%)$, sodium hydroxide solution $(\mathrm{NaOH}, 1 \mathrm{~N}$, cell culture tested), sodium phosphate dibasic, sodium phosphate monobasic, sodium taurocholate, trypan blue solution, and Williams' E medium (WME) were purchased from Sigma-Aldrich (St. Louis, MO). Cholecystokinin-8 (CCK-8) was obtained from Bachem (Bubendorf, Switzerland), and rosuvastatin was obtained from American Radiolabeled Chemicals (St. Louis, MO). Cryopreserved hepatocyte recovery medium, HEPES buffer (1 M, pH 7.4), fetal bovine serum, Dulbecco's phosphate-buffered saline with and without calcium or magnesium, and stabilized L-glutamine (Glutamax, $100 \times$ ) were from Life Technologies (Darmstadt, Germany). High-viability cryohepatocyte recovery medium, insulin-transferrin-selenous acid and bovine serum albumin premix $\left(\mathrm{ITS}^{+}, 100 \times\right)$, and Matrigel phenol red-free were from Corning/BD Biosciences (Bedford, MA). Trypsin/ETDA (0.5/0.2\%) was from PAN Biotech (Aidenbach, Germany). Hepatocyte Thawing Medium, Hepatocyte Culture Medium, Hepatocyte High-Performance Medium, and supplemental reagents $\mathrm{B}$ and $\mathrm{C}$ were purchased from Upcyte Technologies $\mathrm{GmbH}$ (Hamburg, Germany). $\left[{ }^{3} \mathrm{H}\right]$ taurocholic acid $(9.7 \mathrm{Ci} / \mathrm{mmol})$ and $\left[{ }^{3} \mathrm{H}\right] \mathrm{MPP}^{+}(80 \mathrm{Ci} / \mathrm{mmol})$ were purchased from PerkinElmer (Boston, MA). $\left[{ }^{3} \mathrm{H}\right]$ rosuvastatin $(10$ or $20 \mathrm{Ci} / \mathrm{mmol})$, $\left[{ }^{3} \mathrm{H}\right]$ pravastatin $(5 \mathrm{Ci} / \mathrm{mmol}),\left[{ }^{3} \mathrm{H}\right] \mathrm{E}_{2} 17 \beta \mathrm{G}(50 \mathrm{Ci} / \mathrm{mmol})$, and $\left[{ }^{3} \mathrm{H}\right] \mathrm{CCK}-8(98.7$ $\mathrm{Ci} / \mathrm{mmol}$ ) were obtained from American Radiolabeled Chemicals. All peptides and stable isotope-labeled (SIL) peptides were purchased from Proteomedix Frontiers Inc. (Sendai, Japan).

Short-Term and Two-Dimensional Sandwich Culture of Upcyte Hepatocytes. UHH from female Caucasian donors (151-03, 653-03, 10-03) were purchased from Upcyte Technologies $\mathrm{GmbH}$ at a population doubling range of 25-30. Thawing and culturing of cryopreserved UHH was performed as described previously (Schaefer et al., 2016). Briefly, after rapid thawing at $37^{\circ} \mathrm{C}$, cells were suspended in $50 \mathrm{ml}$ Hepatocyte Thawing Medium and sedimented at $90 \mathrm{~g}$ for 5 minutes at room temperature. Viability and cell number, as determined by trypan blue exclusion, were highly consistent among donor batches. Seeding onto collagen I-coated T-150 flasks (Corning/BD Biosciences) was performed at 5$6 \times 10^{3}$ cells $/ \mathrm{cm}^{2}$ in Hepatocyte Culture Medium supplemented with $100 \mathrm{U} / \mathrm{ml}$ penicillin, $100 \mu \mathrm{g} / \mathrm{ml}$ streptomycin, $2 \mathrm{mM}$ L-glutamine, dimethylsulfoxide $(0.5 \%)$, and reagents $\mathrm{B}$ and $\mathrm{C}$ as part of the vendor's proprietary culture media kit. UHH cultures were passaged after 5 days of culture at $95 \%$ humidity, $37^{\circ} \mathrm{C}$, and $5 \% \mathrm{CO}_{2}$ with fresh medium supplied every 48 hours and were further expanded for 2 additional days in collagen I-coated T-150 flasks at 5-6 $\times 10^{3}$ cells $/ \mathrm{cm}^{2}$. Final plating after expansion was done onto collagen I-coated 24 -well plates (Corning/BD Biosciences) at a density of $1.5 \times 10^{5}$ cells $/ \mathrm{cm}^{2}$. Short-term cultures were assessed 4-6 hours after seeding, whereas Matrigel overlay at $0.125 \mathrm{mg} /$ well in Hepatocyte High-Performance Medium [supplemented with $100 \mathrm{U} / \mathrm{ml}$ penicillin, $100 \mu \mathrm{g} / \mathrm{ml}$ streptomycin, $2 \mathrm{mM}$ L-glutamine, dimethylsulfoxide $(0.1 \%)$, and reagent $\mathrm{A}]$ was applied 4-6 hours after seeding for long-term sandwich cultures [sandwich-cultured upcyte human hepatocytes (SCUHH)]. SCUHH were maintained for up to 14 days with daily media change; morphology and confluence was confirmed by light microscopy (Eclipse TS100; Nikon $\mathrm{GmbH}$, Düsseldorf, Germany) prior to experiments

PHH Cultures. cPHH from one male (Hu1601) and three female (371, HC331, HC3-26) Caucasian donors (Supplemental Table 1) were purchased from Life Technologies GmbH, Corning/BD Gentest, and TebuBio GmbH (Offenbach, Germany), respectively. Cells were thawed using the vendor's recovery medium (cryopreserved hepatocyte recovery medium from Life Technologies $\mathrm{GmbH}$; or high-viability cryohepatocyte medium from Corning/BD Gentest), sedimented for 10 minutes at $100 \mathrm{~g}$ at room temperature and finally plated onto collagen Icoated 24-well plates (APSciences Inc., Columbia, MD) at cell densities of 375,000 or 400,000 viable cells per well in WME supplemented with $5 \%$ fetal bovine serum, $15 \mathrm{mM}$ HEPES (pH 7.4), $6.25 \mu \mathrm{g} / \mathrm{ml}$ insulin, $6.25 \mu \mathrm{g} / \mathrm{ml}$ transferrin, $6.25 \mathrm{ng} / \mathrm{ml}$ selenous acid, $5.35 \mu \mathrm{g} / \mathrm{ml}$ linoleic acid, $1.25 \mathrm{mg} / \mathrm{ml}$ bovine serum albumin, $1 \mu \mathrm{M}$ dexamethasone, $100 \mathrm{U} / \mathrm{ml}$ penicillin, $100 \mu \mathrm{g} / \mathrm{ml}$ streptomycin, and $2 \mathrm{mM} \mathrm{L-glutamine} \mathrm{(WME} \mathrm{complete} \mathrm{with} 1 \mu \mathrm{M}$ dexamethasone). Attached cPHH were overlaid 4-6 hours after plating 
with $0.125 \mathrm{mg}$ Matrigel per well in WME complete plus $0.1 \mu \mathrm{M}$ dexamethasone and maintained for up to 7 days at $95 \%$ humidity, $37^{\circ} \mathrm{C}$, and $5 \% \mathrm{CO}_{2}$ with daily medium changes Uptake assays with probe substrates, as well as isolation of total RNA and plasma membrane protein, were conducted at day 0 (4-6 hours after plating; herein referred to as short-term culture) or at day 7 (long-term sandwich culture; SCHH). Cultures were examined by light microscopy for intact morphology and confluence prior to experiments.

Quantitative Reverse Transcription Polymerase Chain Reaction Gene Expression Analysis. Total RNA was isolated as described previously (Schaefer et al., 2016) in parallel to uptake experiments. In brief, three to four wells of cultured cells were pooled for each assay time point. The RNeasy Mini Kit protocol (Qiagen, Hilden, Germany), together with Qiagen QIAshredder homogenization and on-column DNA digestion (RNase-free DNase set; Qiagen), was used for RNA isolation. Purified RNA was quantified spectrophotometrically (NanoDrop 1000 spectrophotometer; Thermo Fisher Scientific, Schwerte, Germany). Total RNA (400 ng/sample) was reverse-transcribed for first-strand cDNA synthesis following the protocol for the High-Capacity cDNA RT Kit (Applied Biosystems, Foster City, CA). Relative mRNA expression of selected hepatic uptake (SCLO1B1, SLCO1B3, SLCO2B1, SLCO1OA1, and SLC22A1) and canalicular expressed transporters $(A B C B 1, A B C C 2, A B C G 2, A B C B 11$, and $S L C 47 A 1)$ was analyzed by quantitative real-time polymerase chain reaction (qRT-PCR) using inventoried TaqMan gene expression assays (Life Technologies/AB; Supplemental Table 2). Threshold cycle values were determined using 7500 Fast software (version 2.06; Applied Biosystems, Darmstadt, Germany). The gene $\beta$-actin served as the endogenous control for normalization of gene expression data and was quantified separately on each assay plate. Threshold cycle values $\geq 36$ were defined as below the limit of quantification (LOQ) and set to zero for subsequent calculations.

Plasma Membrane Protein Extraction and Enzymatic Digestion. Cultured cells (7.2-9.6 $\times 10^{6}$ cells per sample) were harvested from 24-well culture plates using a miniature cell scraper (Biotium Inc., Fremont, CA) and ice-cold phosphate-buffered saline as described previously (Schaefer et al., 2012). Cell collection and centrifugation steps were conducted in LoBind centrifugation tubes (Eppendorf, Hamburg, Germany) and cell pellets were immediately stored at $-80^{\circ} \mathrm{C}$ after snap-freezing in liquid nitrogen. The proteomic method applied in this study was adapted on the basis of techniques developed at Tohoku University (Sendai, Japan). Cell fractionation and separation of the plasma membrane fraction were conducted by differential centrifugation as reported by Sakamoto et al. (2011), Ohtsuki et al. (2012), and Schaefer et al. (2012) with minor modifications. In brief, the combined cell pellet was lysed by sonification for 1.5 minutes at $0^{\circ} \mathrm{C}$ in buffer $\mathrm{A}(0.15 \mathrm{M} \mathrm{KCl}, 0.1 \mathrm{M}$ phosphate buffer, $\mathrm{pH} 7.4$, and $0.5 \mathrm{mM}$ protease inhibitor phenylmethylsulfonylfluoride) using a Bioruptor (Cosmo Bio, Tokyo, Japan). Homogenates were centrifuged at $10,700 \mathrm{~g}$ for 20 minutes at $4{ }^{\circ} \mathrm{C}$, and postnuclear supernatants were collected and sedimented twice at $100,000 \mathrm{~g}$ for 60 minutes at $4^{\circ} \mathrm{C}$. The resulting microsomal pellet was suspended in buffer B ( $0.25 \mathrm{M}$ sucrose and $20 \mathrm{mM}$ Tris-HCl, $\mathrm{pH}$ 7.4), layered on top of a $38 \%(\mathrm{w} / \mathrm{v})$ sucrose solution, and ultracentrifuged at $100,000 \mathrm{~g}$ for 40 minutes at $4^{\circ} \mathrm{C}$. The turbid interface fraction was recovered, suspended in buffer B, and sedimented at $100,000 \mathrm{~g}$ for 60 minutes at $4^{\circ} \mathrm{C}$. Subsequent steps have been modified from the previously published method (Schaefer et al., 2012). Membrane protein solubilization was performed using the Membrane Protein Extraction phase-transfer surfactant (MPEX-PTS) reagent kit (GL Science, Tokyo, Japan) following the assay kit protocol provided with minor modifications (Masuda et al., 2008, 2009). Total protein content of enriched plasma membrane proteins was determined using a 3-(4-carboxybenzoyl)quinolone-2-carboxaldehyde protein quantitation kit (Thermo Fisher, Waltham, MA). MPEX-PTS reagents (containing sodium desoxycholate) were added to $5 \mu \mathrm{g}$ plasma membrane to a final volume of $89 \mu \mathrm{l}$, incubated/denatured at $95^{\circ} \mathrm{C}$ for 5 minutes, and solubilized by subsequent sonication for 10 minutes. Samples were reduced in the presence of $1.3 \mathrm{mM}$ dithiothreitol for 30 minutes at room temperature and alkylated with $2.9 \mathrm{mM}$ iodoacetamide for 30 minutes at room temperature protected from light. After addition of $0.05 \%(\mathrm{w} / \mathrm{v})$ of the trypsin enhancer ProteaseMax (Promega, Madison, WI), sequential proteolytic digestion was performed with lysyl endopeptidase (Wako, Osaka, Japan) for 3 hours at room temperature at an enzyme/protein ratio of 1:100, followed by in-solution digestion with sequencing grade, L-(tosylamido-2-phenyl)ethylchloromethyl ketone-treated trypsin (Promega) for 16 hours at $37^{\circ} \mathrm{C}$ (ratio 1:100) in a final volume of $100 \mu$ l. Digested samples were spiked with SIL peptides (Proteomedix
Frontiers Inc.) as internal standards (ISs) prior to liquid-liquid extraction. An equal volume of ethyl acetate was added, and samples were acidified with $1 \%$ trifluoroacetic acid followed by vortexing and centrifugation. The peptidecontaining aqueous phase was recovered and was desalted using GL-Tips GC (GL Sciences), and the dried residue was dissolved in $0.1 \%$ formic acid.

Surrogate Peptide Selection. Proteotypic signature peptides for quantification of target proteins were designed and chemically synthesized based on an established in silico method and reported selection criteria (Tohoku University algorithm; Kamiie et al., 2008; Uchida et al., 2013). Target peptides selected herein have been used previously by our laboratory or by others (Supplemental Table 3; Sakamoto et al., 2011; Uchida et al., 2011; Ohtsuki et al., 2012; Schaefer et al., 2012; Kunze et al., 2014), respectively, with the exception of peptide probes for OATP1B1 and OATP2B1 (Table 1). Although they were originally designed in avoidance of transmembrane regions, it has become apparent that previous peptides (OATP1B1_peptide A, OATP2B1_peptide A) contain or overlap with transmembrane topological domains of target proteins, respectively, according to updated information and recent protein database searches (Supplemental Fig. 1). Thus, previous peptides no longer comply with our initially specified selection criteria. Alternative proteotypic peptide probes for OATP1B1 and OATP2B1 (OATP1B1_peptide B and OATP2B1_peptide B; Table 1) have been designed, synthesized, and analyzed by Proteomedix Frontiers Inc. to meet the reported criteria (Kamiie et al., 2008; Uchida et al., 2013; Supplemental Fig. 1). Selected ions and multiple reaction monitoring (MRM) transitions for the quantification of transporter peptides have been reported previously (Sakamoto et al., 2011; Uchida et al., 2011; Supplemental Table 3); SRM/MRM conditions for OATP1B1 and OATP2B1 peptides were optimized and defined as described by Sakamoto et al. (2011).

Multiplexed MRM Analysis Using Liquid Chromatography Coupled to Tandem Mass Spectrometry. Surrogate peptides released by tryptic digestion from 10 selected target drug transporters, $\mathrm{Na}^{+} / \mathrm{K}^{+}$-ATPase, and $\gamma$-glutamyl transpeptidase ( $\gamma$-GTP) were simultaneously detected by multiplexed selected reaction monitoring (SRM)/MRM analysis using corresponding SIL peptides as ISs for target peak recognition and normalization as described previously (Sakamoto et al., 2011). In brief, a 5500 QTRAP (AB Sciex, Foster City, CA) electrospray ionization mass spectrometer coupled to an Ultimate 3000 (Dyonex, Amsterdam, The Netherlands) nano-liquid chromatography (LC) system consisting of a loading column [L-Column2 ODS ( $5 \mu \mathrm{m}$ particle size, $300 \mu \mathrm{m}$ inner diameter, $5 \mathrm{~mm}$ length; CERI, Tokyo, Japan) or an ACQUITY UPLC M-Class HSS T3 $(5 \mu \mathrm{m}$ particle size, $300 \mu \mathrm{m}$ inner diameter, $50 \mathrm{~mm}$ length; Waters, Milford, MA] and an analytical C18 nano-LC column [L-Column2 ODS, $3 \mu \mathrm{m}$ particle size, $100 \mu \mathrm{m}$ inner diameter, $150 \mathrm{~mm}$ length; CERI] was used for sample analysis. Mobile phases consisted of aqueous formic acid $(0.1 \%$; $)$ and aqueous acetonitrile ( $95 \%$ with $0.1 \%$ formic acid; B). Purified samples ( $30 \mu \mathrm{l} / \mathrm{sample;} \mathrm{i.e.,}$ $0.75 \mu \mathrm{g}$ protein/sample) were separated and eluted from the analytical column at room temperature, applying a linear gradient from $0 \%$ to $50 \%$ of eluent B at a flow rate on $200 \mathrm{nl} / \mathrm{min}$ with a run time of 60 minutes. The gradient was further increased to $80 \% \mathrm{~B}$ in 10 minutes, then decreased to the initial gradient of $0 \% \mathrm{~B}$ with 0.1 minutes and held at $0 \%$ B for 20 minutes. For data acquisition (070 minutes), the mass analyzer was operated in positive ionization mode and set to MRM with four precursor/product ion transitions (Q1/Q3-1, Q1/Q3-2, Q1/Q3-3, Q1/Q3-4) monitored per target peptide and SIL IS (10-millisecond dwell time per channel), respectively. Optimized parameters for SRM/MRM analysis (four tuned transitions, declustering potential, and collision energy) of target peptides were applied as published previously (Sakamoto et al., 2011; Uchida et al., 2011; Supplemental Table 3). In the case of OATP1B1 and OATP2B1, corresponding parameters are depicted in Table 1 . The spray voltage was set to $2.6 \mathrm{kV}$, and the entrance potential and the collision exit potential were set to $10 \mathrm{~V}$ for all conditions. $\mathrm{Na}^{+} / \mathrm{K}^{+}$-ATPase and $\gamma$-GTP were used as plasma membrane marker proteins to assess the preparation quality of plasma membrane fractions between different samples of SCUHH and SCHH, respectively (Ohtsuki et al., 2012).

Calibration standards and quality control (QC) samples of mixed unlabeled peptides were prepared separately in aqueous formic acid $(0.1 \%)$ by serial dilution of a stock solution $(10 \mathrm{fmol} / \mu \mathrm{l})$ as described (Sakamoto et al., 2011) for accurate bioanalytical quantification. Each calibration curve contained a zero sample and seven nonzero samples ranging from 1 to $100 \mathrm{fmol}$, spiked with a mixture of corresponding IS (20 fmol/IS); the lowest standard was run in duplicate. QC samples were prepared in triplicates for each concentration at 2.5, 15, and $60 \mathrm{fmol}$. Ion count chromatograms were processed using Analyst MultiQuant software 
TABLE 1

SRM/MRM Transitions of Peptides Probes for human OATP1B1 and OATP2B1

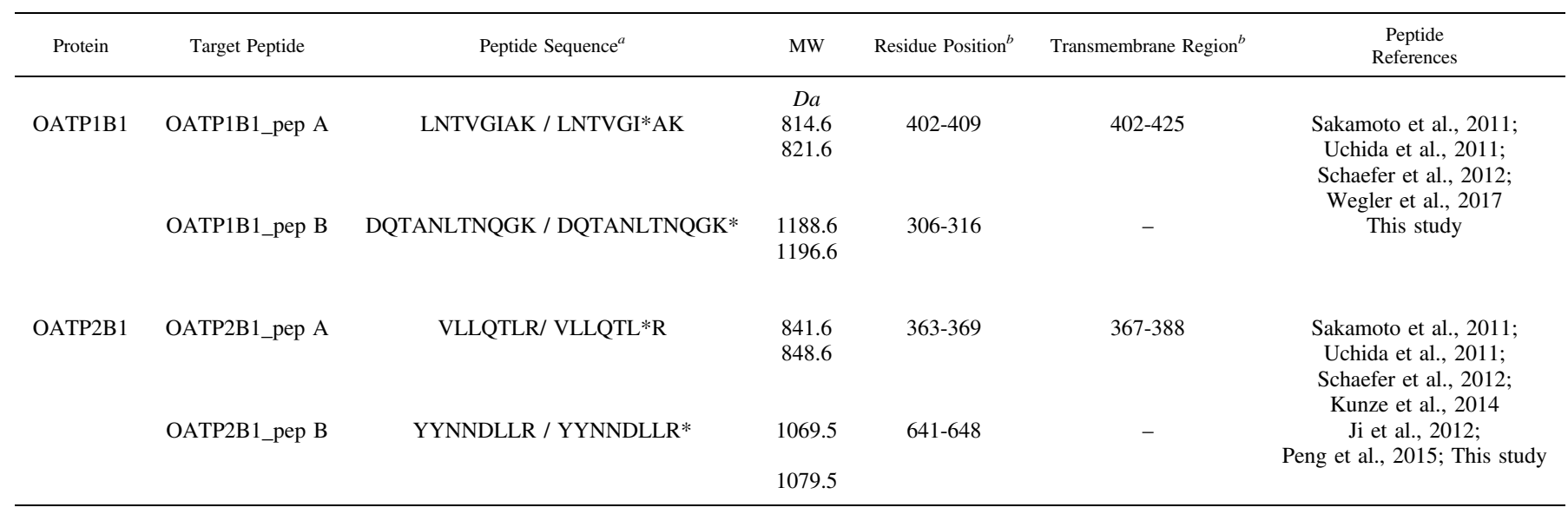

MW, molecular weight.

${ }^{a}$ Letters with an asterisk indicate SIL amino acid residues $\left({ }^{13} \mathrm{C}\right.$ and $\left.{ }^{15} \mathrm{~N}\right)$.

${ }^{b}$ Position (start-end amino acid) of selected peptide within the targeted protein according to the Uniprot database; www.uniprot.org/uniprot/Q9Y616 and www.uniprot.org/uniprot/Q94956

(version 3.0; AB Sciex). Each target peptide level was quantified based on sample peaks identified at the same retention time as the corresponding SIL peptides, and calibration curves were generated for every transition. Concentrations were calculated as the mean of quantitative values derived from three or four out of four MRM transitions. In cases in which fewer than three signal peaks were detectable, the mean concentration was not calculated and the abundance of peptide defined as not quantifiable, according to the methods applied in this study. In case concentrations were found below $1 \mathrm{fmol} / \mu \mathrm{g}$ protein and the corresponding peak area of detected signals of at least two MRM transitions were below 5000 counts, the LOQ was defined as described by Uchida et al. (2011). In brief, the protein level of a signature peptide equivalent to a peak area of 5000 counts was calculated based on the linear regression equations obtained from calibrations curves (determination coefficient $r^{2}>0.99$; Supplemental Table 3). Intra-assay precision and accuracy of quantification were evaluated based on the low-, middle-, and high-amount QC samples, as described previously (Sakamoto et al., 2011).

Determination of Sinusoidal Uptake Activities in Plated PHH and UHH. Cellular accumulation of reference compounds $\left[{ }^{3} \mathrm{H}\right]$ rosuvastatin $(1 \mu \mathrm{M}, 0.5$ $\mu \mathrm{Ci} / \mathrm{ml}),\left[{ }^{3} \mathrm{H}\right]$ pravastatin $(1 \mu \mathrm{M}, 0.5 \mu \mathrm{Ci} / \mathrm{ml}),\left[{ }^{3} \mathrm{H}\right] \mathrm{MPP}^{+}(5 \mu \mathrm{M}, 0.5 \mu \mathrm{Ci} / \mathrm{ml})$, $\left[{ }^{3} \mathrm{H}\right]$ taurocholate $(5 \mu \mathrm{M}, 0.5 \mu \mathrm{Ci} / \mathrm{ml}),\left[{ }^{3} \mathrm{H}\right] \mathrm{E}_{2} 17 \beta \mathrm{G}(1 \mu \mathrm{M}, 0.5 \mu \mathrm{Ci} / \mathrm{ml})$, and $\left[{ }^{3} \mathrm{H}\right]$ CCK-8 $(1 \mu \mathrm{M}, 0.5 \mu \mathrm{Ci} / \mathrm{ml})$ was determined using either conventional monolayer short-term cultures (4-6 hours after plating at high cell density) or long-term cultures in a two-dimensional (2D) sandwich configuration. At designated culture time points, cell layers were rinsed twice and then preincubated with freshly prepared transport buffer solution I $\left(1.8 \mathrm{mM} \mathrm{CaCl}_{2}, 1 \mathrm{mM} \mathrm{MgSO}_{4}, 5.36 \mathrm{mM} \mathrm{KCl}\right.$, $0.41 \mathrm{mM} \mathrm{NaH}_{2} \mathrm{PO}_{4}, 1.19 \mathrm{mM} \mathrm{Na}_{2} \mathrm{HPO}_{4}, 4.17 \mathrm{mM} \mathrm{NaHCO} 3,128 \mathrm{mM} \mathrm{NaCl}$, $20 \mathrm{mM}$ D-glucose, and $15 \mathrm{mM}$ HEPES, adjusted to $\mathrm{pH} 7.2$ with $1 \mathrm{~N} \mathrm{NaOH}$ solution) in the presence or absence of RIF SV $(100 \mu \mathrm{M})$ for 15 minutes at $37^{\circ} \mathrm{C}$. Parallel incubations at $4^{\circ} \mathrm{C}$ without inhibitor were conducted to assess passive diffusion. To start the uptake experiment, $250 \mu \mathrm{l} /$ well prewarmed buffer solution containing a mixture of radiolabeled and unlabeled compound at the defined assay concentration and radioactivity was added onto a preconditioned 24-well plate. An aliquot of $20 \mu \mathrm{l}$ was drawn immediately afterward and analyzed for the actual initial free substrate concentration. Incubations were terminated at different time points by quickly aspirating the substrate solution and washing the cells three times with $500 \mu \mathrm{l} /$ well ice-cold transport buffer. After the plates were dried for 20-30 minutes at $40^{\circ} \mathrm{C}$, cells were lysed with $250 \mu \mathrm{l} /$ well $1 \mathrm{~N} \mathrm{NaOH}$ for at least 20 minutes before adding an equivalent volume of $1 \mathrm{~N} \mathrm{HCl}$. A volume of $400 \mu \mathrm{l} / \mathrm{sample}$ was transferred into a scintillation vial (Pico Prias; PerkinElmer), $5 \mathrm{ml}$ liquid scintillation fluid cocktail (Ultima Gold; PerkinElmer) was added, and radioactivity associated with the cell lysates was measured on a Tri-Carb 2900TR
(PerkinElmer Life and Analytical Sciences, Waltham, MA). Total protein content of the lysate was determined using $20 \mu \mathrm{l} / \mathrm{sample}$ following the manufacturer's protocol for the Pierce BCA protein assay kit (Pierce Biotechnology, Rockford, IL). Activity of NTCP and its contribution to the uptake of rosuvastatin was determined using transport buffer II solution $\left(1.2 \mathrm{mM} \mathrm{CaCl}_{2}, 1.25 \mathrm{mM} \mathrm{MgSO}_{4}\right.$, $4.7 \mathrm{mM} \mathrm{KCl}, 1.2 \mathrm{mM} \mathrm{KH}_{2} \mathrm{PO}_{4}, 25 \mathrm{mM} \mathrm{NaHCO}, 110 \mathrm{mM} \mathrm{NaCl}, 15 \mathrm{mM}$ Dglucose, and $20 \mathrm{mM}$ HEPES, adjusted to $\mathrm{pH} 7.2$ with $1 \mathrm{~N} \mathrm{NaOH}$ solution), sodium $\left(\mathrm{Na}^{+}\right.$)-free transport buffer II (choline chloride and $\mathrm{KHCO}_{3}$ replacing $\mathrm{NaCl}$ and $\mathrm{NaHCO}_{3} ; 1 \mathrm{~N} \mathrm{KOH}$ solution used for $\mathrm{pH}$ adjustment), or transport buffer I containing an excess concentration of taurocholate.

Data Analysis of Uptake Studies. Within one experiment, all incubations were performed in triplicate ( $n=3)$ using confluent cultures of cPHH and UHH from the same seeding, respectively. Data are expressed as means \pm S.D., unless indicated otherwise. Intrinsic sinusoidal uptake activity was expressed either as the uptake rate ( $V_{\text {app }}$; in picomoles per minute per milligram), defined as the measured radioactivity associated with the cells (in disintegrations per minute per well) normalized to incubation time and protein amount (in milligrams protein per well), or as the apparent uptake clearance $\left(\mathrm{CL}_{\mathrm{app}}\right.$; in microliters per minute per milligram), which was calculated from the measured radioactivity normalized to the incubation time and protein amount divided by the applied substrate concentration in the incubation buffer (in disintegrations per minute per microliter). The apparent passive diffusion $\left(\mathrm{CL}_{\text {passive }}\right)$ was derived from uptake experiments conducted at $4^{\circ} \mathrm{C}$, as described above, and subtracted from total hepatic uptake $\left(\mathrm{CL}_{\text {uptake }}\right)$ to determine transporter-mediated permeation processes $\left(\mathrm{CL}_{\text {active }}\right)$. Radioactivity data were corrected for background radioactivity attributed to nonspecific binding of substrate to culture plate surface and/or Matrigel overlay. Background radioactivity was determined by control incubations at $37^{\circ} \mathrm{C}$ or $4^{\circ} \mathrm{C}$ simultaneously in hepatocyte-free Matrigel-containing wells. Inhibition of carrier-mediated uptake was expressed as the percentage of control incubations without inhibitor.

Concentration dependence of uptake processes was analyzed from experiments conducted with eight concentrations by estimating kinetic parameters from the Michaelis-Menten equation (eq. 1) using GraphPad Prism software (version 7.0; GraphPad Software Inc., San Diego, CA):

$$
v=\frac{V_{\max } \times S}{K_{\mathrm{m}}+S}
$$

where $v, S, K_{\mathrm{m}}$ and $V_{\max }$ represent the maximum uptake rate of the substrate (in picomoles per minute per milligram protein), the substrate concentration in the buffer solution (in micromoles), the Michaelis constant (in micromoles) and the 
maximum uptake rate (in picomoles per minute per milligram protein), respectively.

Statistical Analysis. Comparison of uptake rates from incubations performed under different conditions (e.g., in the presence or absence of an inhibitor), using the same hepatic in vitro system, was analyzed using one-way analysis of variance followed by Tukey's multiple-comparisons test. A significant difference was considered at $P$ values $<0.05$. To assess the correlation between quantified protein amounts and hepatic uptake rates, a Pearson's correlation test was conducted. All statistical analyses and graphing were performed using GraphPad Prism software (version 7.0).

\section{Results}

Culture Time-Dependent Expression and Activity of Hepatic Drug Transporters. In terms of selecting appropriate conditions and preculture times for subsequent comparative studies between UHH and $\mathrm{cPHH}$, we assessed the impact of culture duration on the expression of sinusoidal transporters essentially by measuring functional uptake activity. Cellular accumulation of rosuvastatin as an initial functional marker of OATP1B1/1B3 and NTCP activity (Fig. 1A) was determined at different times between day 0 (i.e., 4-6 hours after seeding the cells at confluence in monolayer culture) and day 14 (long-term 2D sandwich culture) and was supported by mRNA expression levels, concomitantly monitored via qRT-PCR in UHH cultures (donor 151-03) from the same seeding. The mRNA expression profiles of each transporter increased after seeding and reached maximum levels between days 5 and 7 . Expression of each transporter decreased thereafter (an example of this is shown for SLCO1B1; Fig. 1A). The bell-shaped expression profile of $S L C O 1 B 1$ correlated with the cultivation time-dependent uptake profile of rosuvastatin (Fig. 1, A and B).
The linear uptake phase for all ensuing accumulation experiments was assessed in uptake experiments conducted for $0.5,1,2,5,10$, and/or 20 minutes. For rosuvastatin, a considerable active uptake component into SCUHH was evident by comparing uptake rates from experiments conducted at a low temperature $\left(4^{\circ} \mathrm{C}\right.$, passive diffusion) and $37^{\circ} \mathrm{C}$, particularly at days 5, 7, and 10 (Fig. 1B). The carrier-mediated uptake was linear up to 5 minutes, considering the uptake profiles of days 5 and 7 displaying maximum accumulation and the highest expression levels (Fig. 1A; Table 2). Consequently, incubation times of 5 minutes were used for all subsequent uptake experiments in SCUHH, centering the evaluations on day 7 or 14 in the case of UHH from donor 653-03. Cells from this particular donor required a longer cultivation period in confluent sandwich culture for maximal uptake of rosuvastatin (data not shown). For taurocholate and $\mathrm{MPP}^{+}$, a linear interval of active uptake was determined up to 5 minutes $\left(\mathrm{MPP}^{+}\right.$) and 10 minutes (taurocholate), respectively. For the latter substrates, a more pronounced difference between the active and passive component of overall transport was observed, facilitating short incubation times of 1 minute (Supplemental Fig. 3). Active uptake kinetics of rosuvastatin $\left(K_{\mathrm{m}}\right.$ and $\left.V_{\max }\right)$ was then estimated applying the defined time of incubation to concentrationdependent uptake experiments at $37^{\circ} \mathrm{C}$ and $4^{\circ} \mathrm{C}$ after 7 days in sandwich culture (Fig. 1C). The $K_{\mathrm{m}}$ value obtained from cultured UHH (6.10 \pm $1.49 \mu \mathrm{M})$ and the respective maximum initial uptake rate $(27.0 \pm$ $2.70 \mathrm{pmol} / \mathrm{min}$ per milligram protein), were found within the range reported by others for rosuvastatin, determined in hepatocytes and transfected cell lines (Nezasa et al., 2003; Ho et al., 2006; Ménochet et al., 2012), thereby supporting further investigation of this hepatic cell model for transporter function under the predetermined assay conditions.
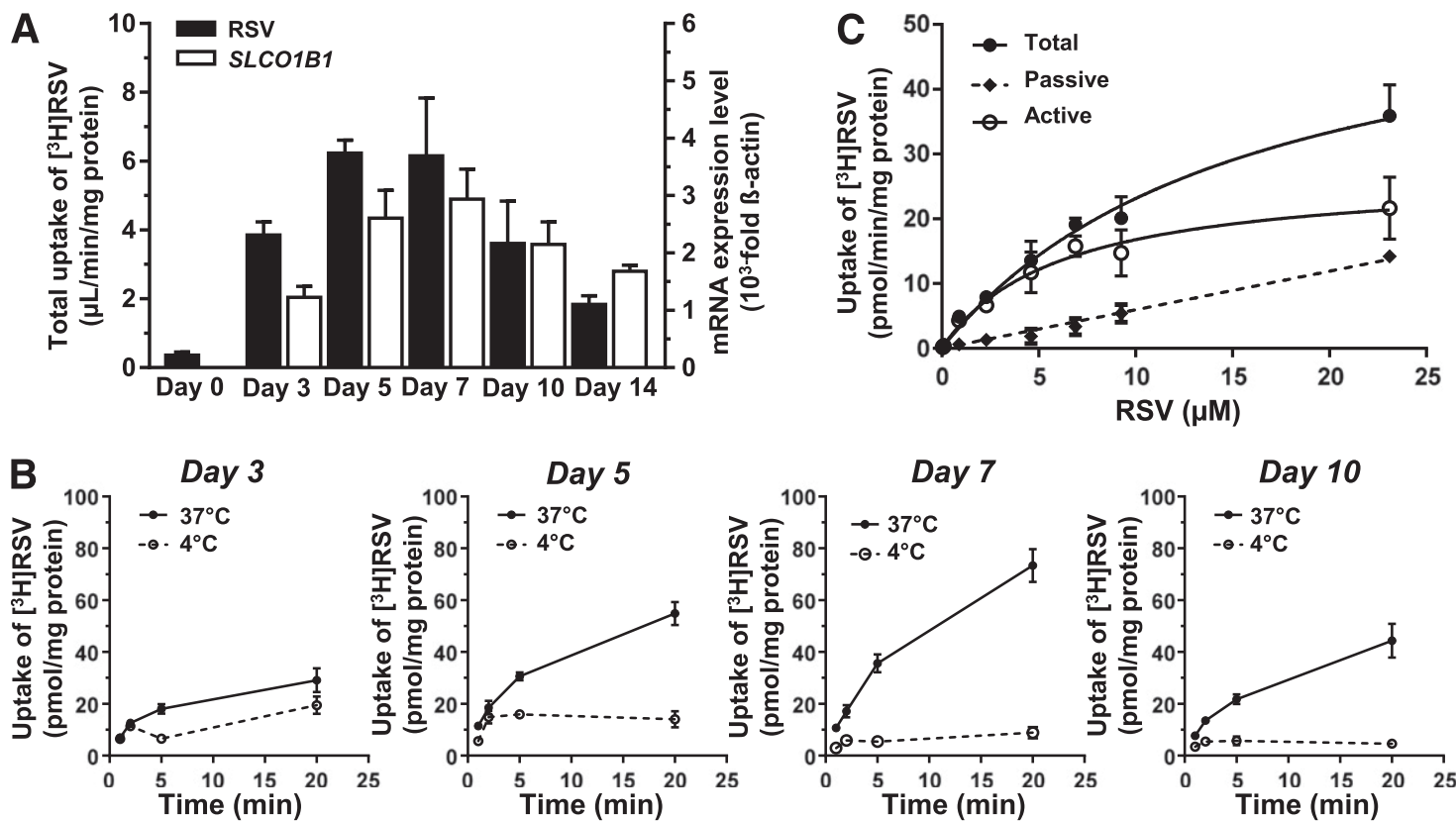

Fig. 1. Culture time-dependent expression and functional uptake of rosuvastatin in plated UHH. (A) Total hepatic uptake CL of $\left[{ }^{3} \mathrm{H}\right]$ rosuvastatin $(1 \mu \mathrm{M})$ was determined in cultured UHH (donor 151-03) at different time points (4-6 hours; i.e., day 0 up to day 14). Each bar represents the mean \pm S.D. of three to six separate measurements $(n=3-6)$ from one to two independent experiments. Expression of OATP1B1/SLCO1B1 was monitored by qRT-PCR using the same batches of cells. Levels of mRNA are depicted relative to endogenous control $\beta$-actin as the mean \pm S.D. $(n=6)$ of two individual experiments. Each sample for mRNA expression analysis represents a pool of a least three wells per time point $(n \geq 3)$. Amplifications were performed in triplicate for each sample $(n=3)$. (B) Time profiles of [ $\left.{ }^{3} \mathrm{H}\right]$ rosuvastatin $(1 \mu \mathrm{M})$ observed in SCUHH at days 3,5,7, and 10. Filled and open circles represent intracellular accumulation determined at $37^{\circ} \mathrm{C}$ and $4{ }^{\circ} \mathrm{C}$, respectively, for $1,2,5$, and 10 minutes. Each data point is expressed as the mean \pm S.D. of three separate measurements from one batch of UHH (error bars are occasionally covered by the symbol). (C) Representative Michaelis-Menten plot of $\left[{ }^{3} \mathrm{H}\right]$ rosuvastatin uptake at day 7 in SCUHH (donor 151-03). Uptake of $\left[^{3} \mathrm{H}\right]$ rosuvastatin was measured at concentrations from 0.05 to $25 \mu \mathrm{M}$ at $4{ }^{\circ} \mathrm{C}$ (dashed line; filled circles) and $37^{\circ} \mathrm{C}$ (solid line, filled circles), respectively; open circles represent carrier-mediated uptake. Uptake experiments were conducted for 5 minutes with the solid line representing the fitted curve. Each point is expressed as the mean \pm S.D. of three separate determinations $(n=3)$. RSV, rosuvastatin. 
TABLE 2

Comparison of drug transporter mRNA expression between short-term cultures and 2D sandwich cultures of UHH

Data are expressed as mean \pm S.E.M. of three separate determinations $(n=3)$ in a single experiment. The average represents the mean \pm S.D. of the different donors $(n=3)$.

\begin{tabular}{|c|c|c|c|c|c|c|c|c|}
\hline \multirow{2}{*}{ Protein } & \multicolumn{2}{|c|}{ Donor 151-03 } & \multicolumn{2}{|c|}{ Donor 653-03 } & \multicolumn{2}{|c|}{ Donor 10-03 } & \multicolumn{2}{|c|}{ Average } \\
\hline & Short-Term Culture & SCUHH & Short-Term Culture & SCUHH & Short-Term Culture & SCUHH & Short-Term Culture & SCUHH \\
\hline \multicolumn{9}{|c|}{$10^{3}$-Fold $\beta$-actin } \\
\hline OATP1B1 & $<\mathrm{LOQ}$ & $1.69 \pm 0.27$ & $<$ LOQ & $1.11 \pm 0.10$ & $<\mathrm{LOQ}$ & $0.079 \pm 0.002$ & $0.00 \pm 0.00$ & $0.960 \pm 0.816$ \\
\hline OATP1B3 & $<\mathrm{LOQ}$ & $<$ LOQ & $<$ LOQ & $<$ LOQ & $<\mathrm{LOQ}$ & $<\mathrm{LOQ}$ & $0.00 \pm 0.00$ & $0.00 \pm 0.00$ \\
\hline OATP2B1 & $<\mathrm{LOQ}$ & $10.8 \pm 0.3$ & $<$ LOQ & $4.60 \pm 0.51$ & $0.723 \pm 0.026$ & $3.31 \pm 0.31$ & $0.241 \pm 0.417$ & $6.24 \pm 4.00$ \\
\hline OCT1 & $0.078 \pm 0.002$ & $9.83 \pm 0.66$ & $0.054 \pm 0.003$ & $2.78 \pm 0.16$ & $<\mathrm{LOQ}$ & $1.57 \pm 0.14$ & $0.044 \pm 0.040$ & $4.73 \pm 4.46$ \\
\hline NTCP & $<\mathrm{LOQ}$ & $8.21 \pm 0.18$ & $<\mathrm{LOQ}$ & $3.76 \pm 0.12$ & $<\mathrm{LOQ}$ & $1.65 \pm 0.06$ & $0.00 \pm 0.00$ & $4.54 \pm 3.35$ \\
\hline MDR1 & $43.4 \pm 2.2$ & $52.0 \pm 0.4$ & $1.17 \pm 0.08$ & $24.5 \pm 2.7$ & $40.8 \pm 2.9$ & $43.2 \pm 1.2$ & $28.5 \pm 23.7$ & $39.9 \pm 14.0$ \\
\hline MRP2 & $37.5 \pm 3.8$ & $36.2 \pm 1.4$ & $2.72 \pm 0.20$ & $18.4 \pm 1.6$ & $55.8 \pm 3.0$ & $19.5 \pm 0.6$ & $32.0 \pm 27.0$ & $24.7 \pm 10.0$ \\
\hline BCRP & $0.594 \pm 0.078$ & $0.273 \pm 0.033$ & $0.855 \pm 0.052$ & $0.704 \pm 0.075$ & $0.255 \pm 0.029$ & $0.104 \pm 0.002$ & $0.568 \pm 0.301$ & $0.360 \pm 0.309$ \\
\hline BSEP & $35.2 \pm 0.4$ & $8.93 \pm 0.09$ & $1.94 \pm 0.20$ & $8.77 \pm 0.40$ & $8.05 \pm 0.50$ & $0.218 \pm 0.034$ & $15.1 \pm 17.7$ & $5.97 \pm 4.98$ \\
\hline MATE1 & $3.76 \pm 0.63$ & $6.90 \pm 0.45$ & $0.161 \pm 0.017$ & $5.65 \pm 0.13$ & $5.93 \pm 0.30$ & $4.19 \pm 0.68$ & $3.28 \pm 2.91$ & $5.58 \pm 1.36$ \\
\hline
\end{tabular}

Transcript levels of hepatic transporters were determined by qRT-PCR of total RNA preparations derived from plated cells, harvested 4-6 h after plating (short-term culture) or after sandwich

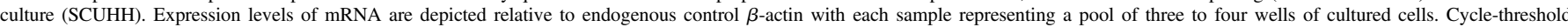
values $\geq 36$ or undetermined template amplifications were defined as below the LOQ and set to zero for calculation of the average.

Findings from initial time-course experiments, conducted in two separate UHH cultures from donor 151-03 (Fig. 1A), were confirmed by subsequent studies focusing on day 0 and days 7 or 14, respectively. In separate short-term monolayer cultures of three different UHH donors [i.e., 4-6 hours after seeding the cells at confluence (day 0)], mRNA expression levels as well as quantified peptides levels of transporter proteins OATP1B1, OATP1B3, OATP2B1, NTCP, and OCT1 encoded by $S L C O 1 B 1, S L C O 1 B 3, S L C O 2 B 1, S L C 1 O A 1$, and $S L C 22 A 1$, respectively, were below the LOQ both at the mRNA (Table 2) and protein levels (Supplemental Table 5). Exceptions to this were OATP2B1 and OCT1, which were partially detectable in short-term cultures of UHH from two donors, albeit at very low levels. However, gene transcripts of sinusoidal transporters could be determined in long-term 2D sandwich cultures (Table 2), suggesting a postculture upregulation of genes encoding for OATP, NTCP, and OCT. Although basal OATP1B1/ $S L C O 1 B 1$ expression was measureable, yet at quantitatively different levels comparing different batches from donor 151-03 (Fig. 1A; Table 2), expression levels of OATP1B3/SLCO1B3 remained below the LOQ for all long-term sandwich cultures evaluated, independent from the batch or donor of UHH evaluated (Table 2). By contrast, expression levels of canalicular efflux transporters were not substantially different between short-term monolayer and long-term sandwich cultures, at least in cells from two of the three donors evaluated. As summarized in Table 2, expression of MDR1/ABCB1, MRP2/ABCC2, breast cancer resistance protein (BCRP)/ABCG2, BSEP/ABCB11, and SLC transporter multidrug and toxic extrusion 1 (MATE1)/SLC47A1 could be readily quantified at the gene level for all UHH donors evaluated.

Comparison between Transporter mRNA and Protein Abundance in 2D Sandwich Cultures of UHH and cPHH. Expression levels determined in SCUHH were compared with those in cPHH from different donors (Supplemental Table 1), which were cultured in the same manner and analyzed in parallel. Relative mRNA expression levels for all sinusoidal SLC transporters were found to be lower in SCUHH compared with those in SCHH (Fig. 2A), with a particularly marked difference observed for SLCO1B3/OATP1B3 (levels below LOQ). However, considerable basal mRNA expression was detected for $S L C O 2 B 1 / \mathrm{OATP} 2 \mathrm{~B} 1$ and SLC10A1/NTCP, with interindividual levels of $4.7 \%-24 \%$ and $1.6 \%-10 \%$ of those in SCHH, respectively (Fig. 2A). Among the canalicular localized drug transporters of the ABC transporter family, noticeably high expression was observed for $A B C B 1 /$ MDR1, exhibiting comparable levels of those found in the primary hepatic model (Fig. 2B). Relative expression levels of all other efflux transporters were lower to different extents in sandwich cultures of different UHH donors compared with SCHH. Nevertheless, ABCC2/ MRP2 and SLC47A1/MATE1 mRNA transcripts were readily detected and were present at levels to approximately one-third of that in $\mathrm{SCHH}$.

Protein abundance of hepatic transporters was analyzed based on a bottom-up quantitative targeted absolute proteomics approach from digested plasma membrane fractions prepared from cultured cells from the same donor and seeding as used for mRNA expression analysis. The sample preparation method described herein was modified based on optimized conditions reported previously (Masuda et al., 2008, 2009; Uchida et al., 2013). MPEX-PTS reagents combined with ProteaseMax and a tandem-combinatorial lysyl endopeptidase/trypsin digestion increased tandem mass spectrometry signals and quantification values of probe peptides, most likely due to enhanced membrane protein solubilization, digestion efficiency, and peptide recovery. Intra-assay variability and validity of the bioanalytical quantification method was investigated in terms of linearity of calibration curves, precision, and accuracy. For all target peptides analyzed, the correlation coefficients $\left(r^{2}\right)$ were greater than 0.992 (Supplemental Table 4A). Inaccuracy was found below $20 \%$ and imprecision values were not greater than $15.4 \%$ based on the mean values of QC samples, derived from three to four transitions (Supplemental Table 4, B and C), except for NTCP (inaccuracy of $20.4 \%$ in the middle-amount QC sample). Representative SRM/MRM chromatograms for standard and QC samples as well as for samples derived from hepatic cell culture are provided in Supplemental Fig. 2. The same proteomic methodology was applied to all samples derived from independent cultures of three different $\mathrm{UHH}$ and $\mathrm{cPHH}$ donors, respectively. Assuming that membrane purification, protein solubilization, and digestion efficiency were similar for primary and genetically modified upcyte hepatocyte samples, we compared quantified peptide levels as a surrogate for the abundance of 10 drug transporters and two membrane markers between the two hepatic in vitro systems evaluated.

In agreement with the mRNA expression data (Table 2), considerable abundance of sinusoidal transporter proteins OATP2B1, OCT1, and NTCP could be demonstrated in samples derived from sandwich cultures (Table 3), whereas quantified levels of OATP1B1 and OATP1B3 were found below the LOQ or were not detected, respectively, in any of the UHH donors evaluated, applying the conditions described herein. In contrast, OATP1B1 and OATP1B3 protein was quantifiable in SCHH from three donors, with a mean of $11.0 \pm 7.6$ $\mathrm{fmol} / \mu \mathrm{g}$ membrane protein and $2.01 \pm 0.12 \mathrm{fmol} / \mu \mathrm{g}$ membrane protein (Supplemental Table 6), respectively, based on the selected peptides 

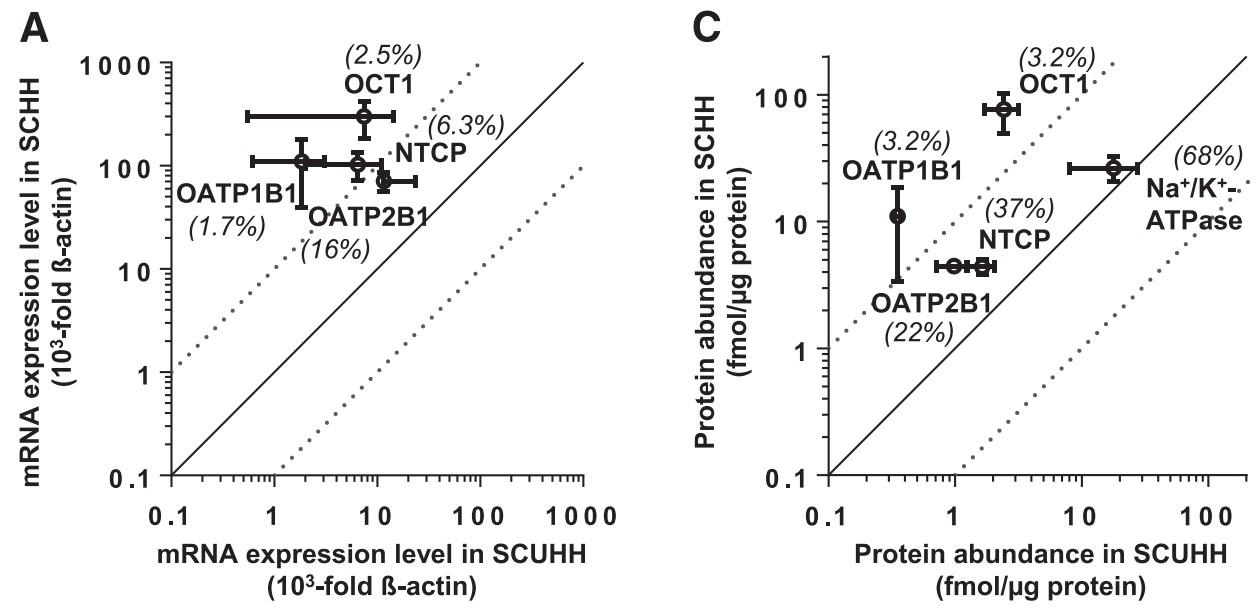

Fig. 2. Abundance of hepatic drug transporters in long-term sandwich cultures of $\mathrm{UHH}$ and $\mathrm{PHH}$. (A-D) Transcript levels and abundance of sinusoidal (A and C) and canalicular (B and D) hepatic transporters were determined in SCUHH and primary hepatocytes $(\mathrm{SCHH})$, respectively, at day 7 or 14 , representing culture days of maximum transport activity determined in SCUHH by uptake experiments with $\left[{ }^{3} \mathrm{H}\right]$ rosuvastatin at different culture time points. Protein abundances (in femtomoles per microgram plasma membrane protein), based on selected probe peptides, were quantified from digested plasma membrane extractions representing the mean \pm S.D. of individual levels derived from three different cultures/donors of SCUHH $(n=3)$ or SCHH $(n=3)$, respectively. Average mRNA levels for each hepatic cell model are expressed relative to endogenous control $\beta$-actin as the mean \pm S.D. of four to nine $(n=$ 4-9) independent studies. The LOQ (as described

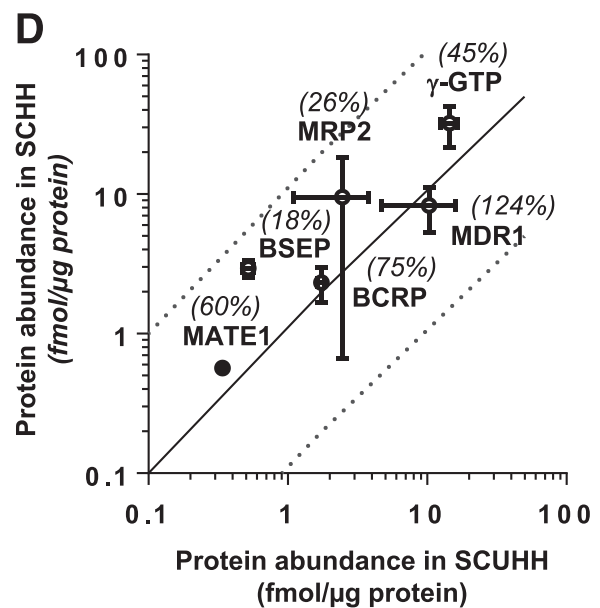
in Materials and Methods) and upper limit of quantification were used for calculation of the average protein levels. In cases in which signature peptides were not quantifiable by the quantitative targeted absolute proteomics method described herein, quantification values were set to zero for calculations of the average; consequently, OATP1B3 levels are not depicted in the logarithmic scaling of the graph. Accordingly, cyclethreshold values $\geq 36$ or undetermined template amplifications were defined as below the LOQ and set to zero for calculation of the average mRNA expression levels. The solid lines represent conformity and dashed lines are the 10-fold error range. Values in brackets express percentages of mRNA or protein amounts relative to those in $\mathrm{SCHH}$ respectively.

mRNA expression level in SCUHH (103-fold B-actin) (fmol/pg protein)

(Table 1; Supplemental Table 3) and the chosen sample preparation method. As depicted in Fig. 2C, representing the average of quantification values derived from individual donors (Table 3), abundances of uptake transporter proteins and the commonly used basolateral membrane marker $\mathrm{Na}^{+} / \mathrm{K}^{+}$-ATPase were lower in SCUHH compared with levels of SCHH. OATP1B1 levels were considerably reduced in SCUHH and, unlike for SCHH (with levels ranging from 4.81 to 19.4 $\mathrm{fmol} / \mu \mathrm{g}$ plasma membrane protein), no donor-related difference in protein abundance was observed. Average quantification levels of OATP2B1 and NTCP in SCUHH based on selected signature peptides ( 0.98 and $1.64 \mathrm{fmol} / \mu \mathrm{g}$ plasma membrane protein, respectively) were approximately one-fifth and one-third of the average amount quantified in SCHH, respectively (Supplemental Table 6). Abundance of OCT1 protein was determined based on the surrogate peptide LSPSFADLFR, in line with previous reports (Supplemental Table 3). Levels in SCUHH were 32-fold lower compared with quantified values in SCHH (Fig. 2C; $>76.4 \pm 26.6 \mathrm{fmol} / \mu \mathrm{g}$ plasma membrane protein), reflecting well the substantial difference observed at the gene level (Fig. 2A).

All five hepatocanalicularly expressed transporter proteins and the canalicular marker enzyme $\gamma$-GTP were detectable in samples from both hepatic systems. Quantified values for MDR1 derived from SCUHH $(10.3 \pm 5.6 \mathrm{fmol} / \mu \mathrm{g}$ plasma membrane protein) were in the same range as levels from $\mathrm{SCHH}(8.28 \pm 2.97 \mathrm{fmol} / \mu \mathrm{g}$ plasma membrane protein $)$. Furthermore, this finding is consistent with gene expression data (Fig. 2B). As shown in Fig. 2D, average protein levels of MPR2, breast cancer resistance protein, BSEP, and MATE1 based on selected signature peptides (Supplemental Table 3) were quantitatively lower but were within 10-fold of the amounts measured in SCHH. Interindividual protein levels of both hepatic models are summarized in Table 3.

Sinusoidal Drug Transporter Activities in Differentiated Cultures of UHH. Carrier-mediated uptake activities of UHH from the same three donors (151-03, 653-03, and 10-03) were assessed by determining accumulation at $37^{\circ} \mathrm{C}$ (total uptake) and $4^{\circ} \mathrm{C}$ (passive diffusion) of rosuvastatin, taurocholate, and $\mathrm{MMP}^{+}$as typical substrates for OATP1B1/1B3/2B1 (Ho et al., 2006; Kitamura et al., 2008), NTCP (Trauner and Boyer, 2003), and OCT1 (Umehara et al., 2007), respectively. Uptake of radiolabeled substrates was reproducibly demonstrated in long-term sandwich cultures of UHH (Table 4). The highest total uptake clearance $\left(\mathrm{CL}_{\text {uptake }}\right)$ in SCUHH was measured for $\mathrm{MPP}^{+}$, whereas a considerably low $\mathrm{CL}_{\text {uptake }}$ was observed for rosuvastatin. Furthermore, uptake rates were significantly higher at $37^{\circ} \mathrm{C}$ than at $4^{\circ} \mathrm{C}$ (except for rosuvastatin in cells from donor 653-03), indicating a substantial contribution of carrier-mediated transport to overall uptake of reference drugs evaluated (Supplemental Fig. 4). $\mathrm{CL}_{\text {uptake }}$ of rosuvastatin, taurocholate, and $\mathrm{MPP}^{+}$was lower in all SCUHH compared with that in SCHH, the extent of which was donor dependent (2.7- to 4.6-fold, 2.0- to 3.5-fold, and 1.2- to 2.7-fold, respectively; Table 3). Nevertheless, percentages of transportermediated uptake $\left(\mathrm{CL}_{\text {active }}\right)$ for each substrate were generally in line with the extent of active contributions observed in SCHH. For rosuvastatin and taurocholate, interindividual variation in $\mathrm{CL}_{\text {uptake }}$ was similar between both hepatic models, with a coefficient of variance $(\mathrm{CV})$ 
TABLE 3

Protein abundance of hepatic drug transporters in sandwich cultures of UHH and PHH

Concentrations based on selected signature peptides are given as total amount of plasma membrane protein (femtomoles per microgram plasma membrane protein) and are expressed as the mean \pm S.E.M. of triplicates or quadruplicates $(n=3-4$ MRM transitions) of a single experiment.

\begin{tabular}{|c|c|c|c|c|c|c|}
\hline \multirow{2}{*}{ Protein } & \multicolumn{3}{|c|}{ SCUHH } & \multicolumn{3}{|c|}{$\mathrm{SCHH}$} \\
\hline & Donor 151-03 & Donor 653-03 & Donor $10-03$ & Donor Hu1601 & Donor HC3-31 & Donor 371 \\
\hline & \multicolumn{6}{|c|}{$\mathrm{fmol} / \mu \mathrm{g}$} \\
\hline OATP1B1 & $<$ LOQ (0.338) & $0.376 \pm 0.063$ & <LOQ (0.338) & $4.81 \pm 0.25$ & $19.4 \pm 1.08$ & $8.73 \pm 0.74$ \\
\hline OATP1B3 & NQ & NQ & NQ & $1.96 \pm 0.73$ & $1.93 \pm 0.48$ & $2.15 \pm 0.49$ \\
\hline OATP2B1 & $1.29 \pm 0.13$ & $0.849 \pm 0.064$ & $0.802 \pm 0.133$ & $4.51 \pm 0.30$ & $4.18 \pm 0.34$ & $4.70 \pm 0.64$ \\
\hline OCT1 & $1.79 \pm 0.53$ & $3.20 \pm 0.47$ & $2.28 \pm 0.26$ & >ULQ (100) & $81.7 \pm 16.5$ & $47.7 \pm 10.6$ \\
\hline NTCP & $1.95 \pm 0.82$ & $1.19 \pm 0.18$ & $1.79 \pm 0.47$ & $5.11 \pm 0.41$ & $4.00 \pm 0.60$ & $4.12 \pm 0.79$ \\
\hline MDR1 & $7.28 \pm 0.95$ & $6.83 \pm 0.71$ & $16.8 \pm 4.4$ & $7.70 \pm 0.87$ & $11.5 \pm 0.7$ & $5.65 \pm 0.59$ \\
\hline MRP2 & $4.00 \pm 0.21$ & $1.43 \pm 0.12$ & $1.96 \pm 0.08$ & $19.7 \pm 2.94$ & $5.19 \pm 0.28$ & $3.67 \pm 0.31$ \\
\hline BCRP & $1.63 \pm 1.06$ & $1.78 \pm 0.40$ & $1.81 \pm 0.60$ & $1.74 \pm 0.37$ & $3.02 \pm 0.85$ & $2.21 \pm 0.53$ \\
\hline BSEP & $<\operatorname{LOQ}(0.467)$ & $0.570 \pm 0.036$ & $0.523 \pm 0.049$ & $3.22 \pm 0.82$ & $2.47 \pm 0.14$ & $3.15 \pm 0.14$ \\
\hline MATE1 & $<$ LOQ $(0.334)$ & $0.352 \pm 0.066$ & $<$ LOQ $(0.334)$ & $0.525 \pm 0.138$ & $0.614 \pm 0.045$ & $0.566 \pm 0.078$ \\
\hline $\mathrm{Na} / \mathrm{K}$-ATPase & $6.45 \pm 0.54$ & $24.5 \pm 1.8$ & $22.7 \pm 1.4$ & $33.2 \pm 3.52$ & $23.6 \pm 3.44$ & $22.7 \pm 1.68$ \\
\hline$\gamma$-GTP & $12.2 \pm 2.3$ & $15.9 \pm 2.4$ & $15.5 \pm 0.6$ & $42.8 \pm 2.6$ & $21.5 \pm 0.7$ & $32.2 \pm 4.3$ \\
\hline
\end{tabular}

Abundance of surrogate peptides for canalicular and sinusoidal transporter proteins was quantified from digested plasma membrane extractions derived from sandwich-cultured upcyte and primary hepatocytes (SCUHH and SCHH), respectively. In cases in which concentrations were found below $1 \mathrm{fmol} / \mu \mathrm{g}$ protein and the corresponding peak area of detected signals of at least two MRM transitions was below 5000 counts, the LOQ was defined as described by Uchida et al. (2011). In brief, the protein level of a signature peptide equivalent to a peak area of 5000 counts was calculated based on the linear regression equations obtained from calibrations curves (determination coefficient $r^{2}>0.99$; Supplemental Table 4). If signal peaks were not detectable for two or more MRM transitions of a signature peptide, the corresponding transporter protein was defined as not quantifiable and was considered not to be present in the corresponding UHH culture, applying the quantitative targeted absolute proteomics method described herein. LOQ and ULQ values were as follows: LOQ $0.338 \mathrm{fmol} / \mu \mathrm{g}$ plasma membrane protein; LOQ $\mathrm{BSEP}=0.467 \mathrm{fmol} / \mu \mathrm{g}$ plasma membrane protein; and ULQocT1 $=100 \mathrm{fmol} / \mu \mathrm{g}$ plasma membrane protein. NQ, not quantifiable; ULQ, upper limit of quantification.

between $28 \%$ and $34 \%$; however, the variation for $\mathrm{MPP}^{+}$was higher in SCUHH (37\% CV) than in SCHH $(5.5 \% \mathrm{CV})$.

To differentiate further between $\mathrm{Na}^{+}$-dependent and OATP-mediated uptake activity in SCUHH, uptake rates of CCK-8 and pravastatin (as well as $\mathrm{E}_{2} 17 \beta \mathrm{G}$; data not shown) were determined in SCUHH (donor 151-03) and SCHH at day 7. Uptake rates of CCK-8 and pravastatin were substantially lower in SCUHH compared with those in SCHH (Fig. 3). There was no statistical difference between incubations at $37^{\circ} \mathrm{C}$ and

TABLE 4

Comparison of Hepatic Uptake Activities between Long-term cultured UHH and PHH

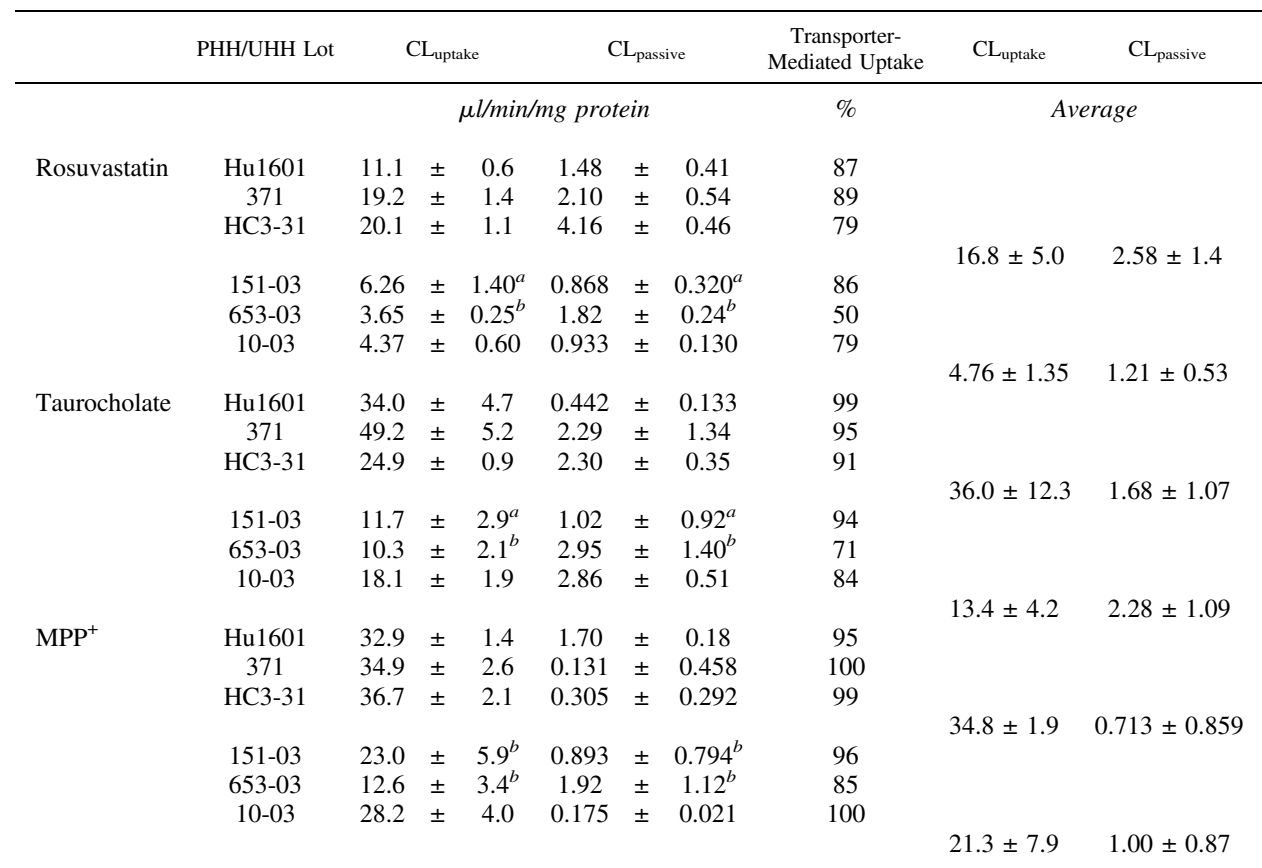

Uptake clearances $\left(\mathrm{CL}_{\text {uptake }}\right)$ of rosuvastatin, taurocholate, and $\mathrm{MPP}^{+}$were determined from transport studies conducted for up to 5 minutes at $37^{\circ} \mathrm{C}$ on day 7 or 14 (donor 653-03) in sandwich culture using three different donors of UHH and PHH, respectively. Passive clearance $\left(\mathrm{CL}_{\text {passive }}\right)$ was appraised from control incubations performed at $4{ }^{\circ} \mathrm{C}$.

${ }^{a}$ Data represent the mean \pm S.D. determined using all replicates of three to four independent experiments $(n=9-12)$.

${ }^{b}$ Data represent the mean \pm S.D. determined using all replicates of two independent experiments $(n=6)$ 
A

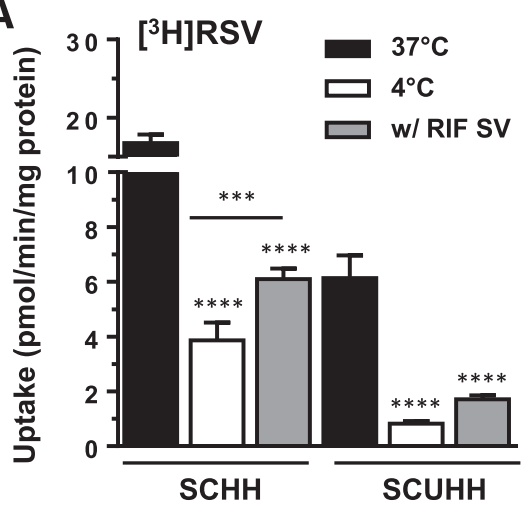

B

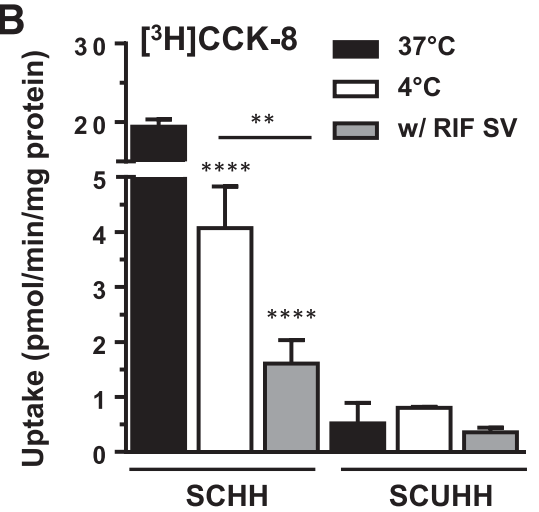

C

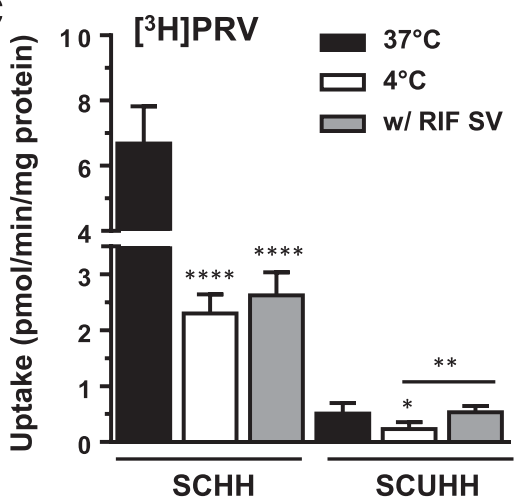

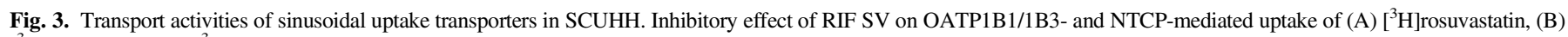

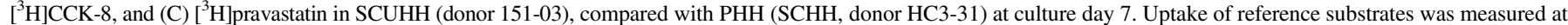

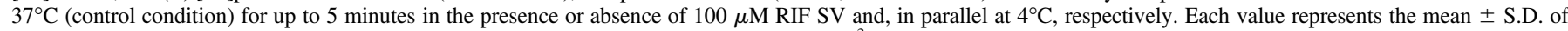

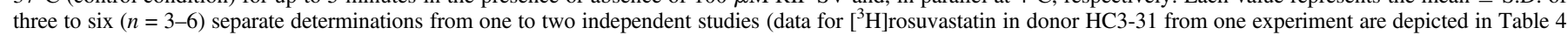

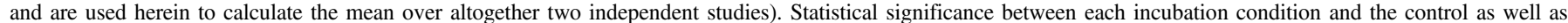

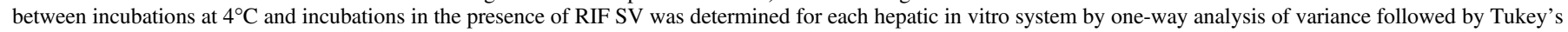
post hoc test $(* P<0.05$; $* * P<0.01$; ***P $<0.001$; **** $P<0.0001)$. PRV, pravastatin; RSV, rosuvastatin; CCK-8, cholecystokinin-8.

$4^{\circ} \mathrm{C}$, nor was the uptake inhibited by RIF SV, indicating a lack of carriermediated contributions to the overall uptake of these reference substrates in SCUHH. In contrast, uptake of rosuvastatin (Fig. 3A) was substantially decreased to $28 \%$ of the control accumulation rate by RIF SV in SCUHH. In addition, RIF SV inhibited OATP-mediated uptake of rosuvastatin, $\mathrm{CCK}-8$, and pravastatin by $64 \% \pm 1.6 \%, 92 \% \pm 2.2 \%$, and $61 \% \pm 6.2 \%$ in $\mathrm{SCHH}$, respectively (Fig. 3). In both hepatic culture models, differences in uptake rates of rosuvastatin and pravastatin observed between $4^{\circ} \mathrm{C}$ and $37^{\circ} \mathrm{C}$ incubations containing RIF SV (1.6- to 2.1-fold and 1.1- to 2.3-fold, respectively) might be a result of altered fluidity of the plasma membrane at low temperature, restricting passive diffusion (Kimoto et al., 2011). Incomplete inhibition of active processes (Webborn et al., 2007) under the experimental conditions applied herein might also explain this finding. Interestingly, cellular accumulation of CCK-8 was higher at $4{ }^{\circ} \mathrm{C}$ compared with incubations at $37^{\circ} \mathrm{C}$ with RIF $\mathrm{SV}$. We speculate that RIV SV displaced CCK-8 from its temperaturedependent binding to cells or other proteins present in the incubation matrix, potentially leading to reduced accumulation rates observed. However, the estimated contribution of passive diffusion to total uptake of CCK-8 (21\%; based on substrate accumulation determined at $4{ }^{\circ} \mathrm{C}$ and depicted for $\mathrm{SCHH}$ in Fig. 3) was found in line with reported values (28.6\%; Kunze et al., 2014).

NTCP-Mediated Uptake of Rosuvastatin in UHH. Since OATP1B3 and OATP1B1 at the mRNA and protein levels were not detected or only at very low levels in SCUHH using our methods, respectively (Tables 2 and 3), we investigated whether quantified peptide levels, considered as a surrogate for NTCP and OATP2B1 protein abundance in the corresponding in vitro system, could be associated with the active uptake of rosuvastatin in SCUHH from three different donors. Indeed, our data (Fig. 4A) indicated that NTCP and/or OATP2B1, rather than OATP1B1 protein abundance correlate with the active uptake of rosuvastatin in SCUHH.

In a separate study using different batches of cells (i.e., different seeding, which was not used for mRNA or quantitative proteomics analysis), the sodium $\left(\mathrm{Na}^{+}\right)$-dependent uptake of rosuvastatin and taurocholate into SCHH and SCUHH under conditions of depleted extracellular $\mathrm{Na}^{+}$or in excess concentrations of taurocholate was investigated. Although uptake clearance of taurocholate $(7.78 \pm 1.55$ $\mu \mathrm{l} / \mathrm{min}$ per milligram total protein) determined under control conditions $\left(37^{\circ} \mathrm{C}, \mathrm{Na}^{+}\right.$-containing buffer) was comparable to previous experiments (Table 4$)$, uptake of rosuvastatin $(2.46 \pm 0.25 \mu \mathrm{l} / \mathrm{min}$ per milligram total protein) was notably reduced in this particular batch of SCUHH. In SCHH, uptake clearance of both substrates $(18.5 \pm 3.1$ and $16.1 \pm 2.3$ $\mu 1 /$ min per milligram total protein for taurocholate and rosuvastatin, respectively) were well in line with previous results (Table 4). In the absence of extracellular $\mathrm{Na}^{+}$, hepatic uptake of taurocholate was substantially decreased by $74 \%$ in both hepatic models (Fig. 4B), whereas the uptake of rosuvastatin uptake was only reduced by $27 \%$ in SCHH (Fig. 4C). By contrast, $\mathrm{Na}^{+}$-depletion caused a $46 \%$ decrease of rosuvastatin uptake in SCUHH, suggesting a higher contribution of NTCP to the total hepatic uptake of this substrate in SCUHH compared with $\mathrm{SCHH}$. In the presence of $\mathrm{Na}^{+}$, an excess of unlabeled taurocholate significantly inhibited the uptake of radiolabeled taurocholate (Fig. 4B) in SCHH (95\% inhibition) as well as in SCUHH (85\% inhibition). A marked inhibition was also observed in the hepatic uptake of rosuvastatin (Fig. 4C), yet to a higher extent in SCHH (74\%) than in SCUHH (55\%).

\section{Discussion}

Previously, UHH have been characterized regarding their hepatic phenotype and metabolic capabilities (Schaefer et al., 2016; Tolosa et al., 2016). However, sinusoidal and canalicular transport properties, as key attributes of differentiated hepatocytes, have not yet been described for $\mathrm{UHH}$

Results presented herein indicate that sinusoidal membrane transporters were poorly expressed or even undetectable (Table 2) in shortterm cultures of UHH, in contrast with cPHH cultured for 4-6 hours (data not shown; Kotani et al., 2011). Pursuant to this, uptake activities of OATP1B1/1B3/2B1, NTCP, and OCT1 in short-term cultures of $\mathrm{UHH}$ were shown to be considerably lower compared with $\mathrm{cPHH}$ (unpublished data), according to cellular accumulation studies with reference substrates rosuvastatin (Fig. 1, day 0), taurocholic acid, and $\mathrm{MPP}^{+}$(data not shown). This finding is in agreement with data from others, who showed that cPHH maintain functional expression of uptake transporters at transporter- and/or lot-specific levels (Jigorel et al., 2005; Kotani et al., 2011; Kimoto et al., 2012). In addition to cryopreservation, which generally impacts uptake activity (Badolo et al., 2011), UHH additionally pass several subculture steps involving proteolytic dissociation prior to seeding at high cell density. This procedure likely contributes to the loss of functional cell surface proteins (Huang et al., 2010), which presumably impedes the use of suspended or short-term 

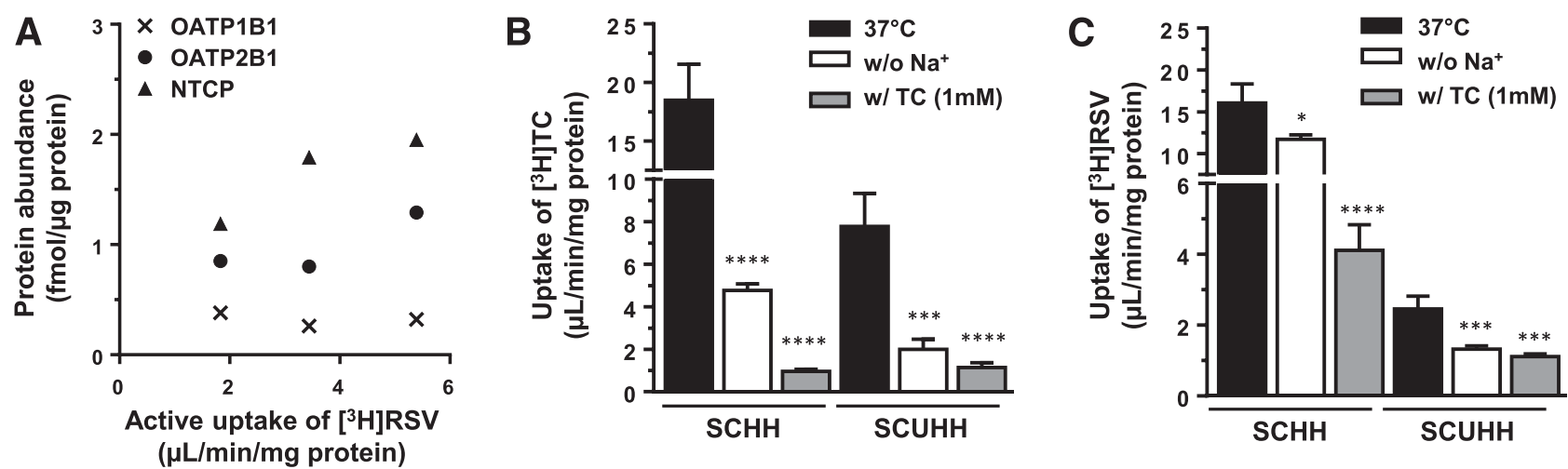

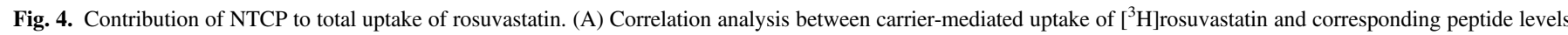

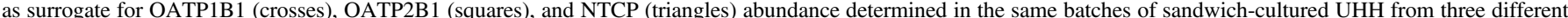

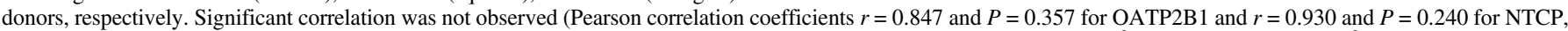

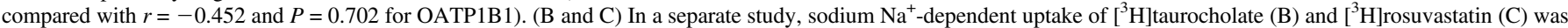

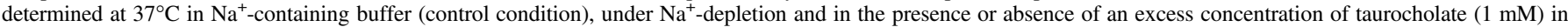

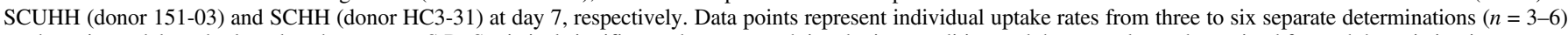

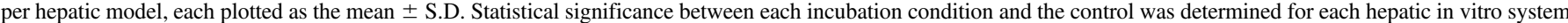
by one-way analysis of variance followed by Tukey's post hoc test $\left({ }^{*} P<0.05\right.$; $* * * P<0.001$; $\left.* * * *<0.0001\right)$. RSV, rosuvastatin; TC, taurocholate.

(i.e., 4-6 hour) cultured UHH for uptake studies. However, according to our findings, $\mathrm{UHH}$ in a 2D collagen/Matrigel sandwich configuration (SCUHH) recover from trypsinization, are able to restore membrane proteins, and exhibit considerable expression of OATP1B1, OATP2B1, NTCP, and OCT1 after 5-7 days. This culture time-dependent increase in expression, notably the lack of functional uptake in short-term cultures, might also be attributed to the proliferation-inducing cytokine OSM. It has been shown that OSM, similarly to interleukin-6, adversely affects expression of sinusoidal SLC-transport proteins (Le Vee et al., 2011). Thus, the progressing uptake activity in sandwich culture may be linked to OSM withdrawal and consequently to an induced growth arrest and differentiation into mature hepatocyte-like cells with reported functional polarization (Levy et al., 2015). This hypothesis justifies the necessity of preculture periods at confluence prior to end-point measurements and is in line with previous results on cultivation timedependent functionality of P450s in SCUHH (Schaefer et al., 2016). Therefore, investigations were performed after 7 or 14 days (donor 65303) in sandwich culture.

The expression of canalicular efflux pumps seemed to be preserved in SCUHH based on qRT-PCR and peptide-based LC coupled to tandem mass spectrometry analysis. MDR1/ABCB1, MATE1/SLC47A1, and MRP2/ABCC2 were notably expressed at donor-dependent levels (Fig. 2, B and D; Table 3), corresponding to a generally more stable expression of hepatic efflux transporters, as previously reported for PHH, HepaRG cells, and HuH-7 cells (Yang et al., 2012; Le Vee et al., 2013; Jouan et al., 2016). Although expression of sinusoidal uptake transporters was considerably higher than that reported for hepatoma cell line HuH-7 or HepG2 cells (Guo et al., 2011; Jouan et al., 2016), mRNA levels and quantified amounts of selected peptides were remarkably reduced in SCUHH compared with SCHH (Fig. 2, A and C). The most pronounced differences were observed for OATP1B1, and particularly for OATP1B3, coinciding with findings reported for differentiated HepaRG cells (mRNA levels were $7.0 \%$ and $0.6 \%$ of those in $\mathrm{cPHH}$, respectively; Le Vee et al., 2013). Similar to OATP1B3 in HepaRG cells (Kotani et al., 2012), OATP1B3 mRNA and protein, based on the selected peptide, was virtually undetectable in SCUHH compared with $\mathrm{SCHH}$ at all time points evaluated. In addition, quantified OCT1 peptide levels, as well as transcript levels, were profoundly lower in SCUHH, contradicting the active uptake of $\mathrm{MPP}^{+}$demonstrated in SCUHH. Lacking evidence of analytical/experimental effects, the OCT1 expression-activity discrepancy remains to be further investigated.
Variability of reported mass spectrometry-based protein quantification values, likely biased by different methodological procedures applied and/or signature peptides selected, (Balogh et al., 2012; Badée et al., 2015; Peng et al., 2015; Harwood et al., 2016; Wegler et al., 2017), hampers direct comparison of absolute protein abundances among different laboratories. Considering this general limitation, quantified peptide levels in $\mathrm{SCHH}$, measured under the chosen conditions, were yet within the range of published abundances, albeit OCT1 levels were found above reported values (Supplemental Table 6; Schaefer et al., 2012; Vildhede et al., 2015). Based on reported beneficial effects on solubilizing and digesting hydrophobic proteins by use of MPEX-PTS reagents and application of a tandem-combinational in-solution protocol (Masuda et al., 2008, 2009; Uchida et al., 2013), we assume that observed discrepancies are rather linked to our sample preparation method than to biologic variability. In this context, quantitative protein values determined herein as supportive data, together with mRNA levels, were intended to underpin differences observed in active uptake between the two hepatic models evaluated.

On a functional level, we primarily used rosuvastatin to assess overall OATP- and NTCP-mediated uptake properties of SCUHH and SCHH, as suggested by Ménochet et al. (2012). Uptake of rosuvastatin was saturable (Fig. 1) and was found appropriate to display interindividual variations observed at the gene and protein levels. However, unlike the considerably different OATP1B1 abundances in SCHH (Table 3; Kimoto et al., 2012), OATP1B1/SLCO1B1 expression showed no substantial interindividual variation in $\mathrm{SCUHH}$, indicating that differences in $\mathrm{CL}_{\text {uptake }}$ observed between $\mathrm{UHH}$ donors could not be contributed solely to OATP1B1 activity. Given that rosuvastatin is a substrate of all three OATP isoforms as well as NTCP (Ho et al., 2006; $\mathrm{Bi}$ et al., 2013), we attributed interindividual variations observed in the hepatic uptake of rosuvastatin by SCUHH to NTCP and/or OATP2B1. Indeed, besides the profound impact of the genetic variants SLCO1B1*1B/*5/*15 on rosuvastatin pharmacokinetics (Giacomini et al., 2010; Yoshida et al., 2013; Patel et al., 2016), it has been shown that the $N T C P * 2$ variant affects cellular accumulation of rosuvastatin compared with the NTCP wild type (Choi et al., 2011). To support our assumption, and lacking information on the polymorphic forms of SLCO genes present in UHH donors evaluated, we first showed that rosuvastatin uptake was significantly inhibited by RIF SV (Fig. 3), a potent inhibitor of OATPs, but also of NTCP (Bi et al., 2013). By selecting additional OATP reference substrates without a known 
profound contribution of OATP2B1 or NTCP, i.e. CCK-8 (OATP1B3/1B1; Ishiguro et al., 2006), pravastatin (OATP1B1; Hagenbuch and Gui, 2008), and $\mathrm{E}_{2} 17 \beta \mathrm{G}$ (mainly OATP1B1; Hirano et al., 2004), we could link reduced OATP1B1/1B3 activity in SCUHH to markedly poor expression observed for the respective genes. This observation may also relate to $S L C O 1 B 1 / 1 B 3$ genetic mutations, as discussed for HepaRG cells (Kotani et al., 2012). In contrast with the lack of correlation between OATP1B1/1B3 protein abundance and active uptake of rosuvastatin $\left(\mathrm{CL}_{\text {active }}\right)$ in $\mathrm{SCUHH}$, a considerable quantitative protein expression-activity relationship was observed for NTCP-mediated uptake of taurocholate. The $\mathrm{CL}_{\text {active }}$ of taurocholate was clearly attributed to NTCP in both hepatic models (Fig. 4B), to a similar extent as that reported by Bi et al. (2013), confirming functional expression of NTCP in SCUHH. However, as hypothesized, the contribution of NTCP to $\mathrm{Na}^{+}$-dependent uptake of rosuvastatin was found to be higher in SCUHH (46\%-55\%), compared with our own (27\%) and reported (28\%-35\%) data for SCHH (Fig. 4; Ho et al., 2006; Kitamura et al., 2008; Elsby et al., 2012; Bi et al., 2013). Furthermore, given that taurocholate is also a substrate of several OATPs (KullakUblick et al., 2001; Takikawa, 2002), we assumed that the excess of taurocholate also inhibited OATP-associated $\mathrm{CL}_{\text {active }}$ of rosuvastatin in SCHH (74\% inhibition). By contrast, and potentially attributed to the lack of OATP1B1/1B3 expression and activity in SCUHH, taurocholate failed to increase the inhibitory effect associated with $\mathrm{Na}^{+}$-depletion. Apart from NTCP, abundance of OATP2B1 was evident in SCUHH membrane fractions. Thus, along with the overlapping substrate specificity of OATP isoforms (Kitamura et al., 2008), it appears reasonable to assume profound contribution of OATP2B1, in addition to NTCP, to the active uptake of rosuvastatin in SCUHH. Based on our results, we speculate that both SLC transporters are able to compensate, at least to some extent, for low levels or absence of OATP1B1/1B3 activity in the uptake of xenobiotics with overlapping OATP/NTCP specificity, as discussed previously (Bi et al., 2013). Future, more comprehensive studies including additional reference drugs with diverse substrate specificity of NTCP and OATPs are required to strengthen this hypothesis.

In our efforts to evaluate the utility of SCUHH as an in vitro tool to assess hepatic uptake-mediated clearance processes, the benchmark of SCHH, particularly regarding OATP1B1/1B3, was not met. Despite this limitation, SCUHH maintain expression of several canalicular efflux pumps and SLC uptake transporters at relevant levels. In addition, preliminary results (Supplemental Fig. 5) indicated that expression of $S L C O 1 B 1 / 1 B 3$ and SLCO2B1 in SCUHH can be modulated by change of culture medium, which may be related to the presence of dexamethasone and/or other activators of nuclear receptors (e.g., pregnane $\mathrm{X}$ receptor or farnesoid $\mathrm{X}$ receptor) and subsequently suggest the possibility to upregulate OATP expression in SCUHH (Jigorel et al., 2006; Stieger and Hagenbuch, 2014). To what extent remains to be investigated.

Applying the culture conditions described herein, SCUHH demonstrated NTCP-, OATP2B1-, and OCT1-mediated uptake and thus might be considered as a useful tool to elucidate compensatory and/or additional uptake pathways for OATP1B1/1B3 substrates.

\section{Acknowledgments}

We thank Asami Saito, Kaori Makino, and Katsuya Kominami for valuable technical support with quantitative proteomics and Shinobu Suzuki for greatly supporting this collaborative work.

\section{Authorship Contributions}

Participated in research design: Schaefer, Schänzle.

Conducted experiments: Schaefer, Morinaga.

Performed data analysis: Schaefer, Morinaga.
Wrote or contributed to the writing of the manuscript: Schaefer, Matsui, Schänzle, Bischoff, Süssmuth.

\section{References}

Aninat C, Piton A, Glaise D, Le Charpentier T, Langouët S, Morel F, Guguen-Guillouzo C, and Guillouzo A (2006) Expression of cytochromes P450, conjugating enzymes and nuclear receptors in human hepatoma HepaRG cells. Drug Metab Dispos 34:75-83.

Badée J, Achour B, Rostami-Hodjegan A, and Galetin A (2015) Meta-analysis of expression of hepatic organic anion-transporting polypeptide (OATP) transporters in cellular systems relative to human liver tissue. Drug Metab Dispos 43:424-432.

Badolo L, Trancart MM, Gustavsson L, and Chesné C (2011) Effect of cryopreservation on the activity of OATP1B1/3 and OCT1 in isolated human hepatocytes. Chem Biol Interact 190: $165-170$.

Balogh LM, Kimoto E, Chupka J, Zhang H, and Yunrong L (2012) Membrane protein quantification by peptide-based mass spectrometry approaches: studies on the organic anion-transporting polypeptide family. J Proteomics Bioinform 6:229-236.

Bi YA, Qiu X, Rotter CJ, Kimoto E, Piotrowski M, Varma MV, Ei-Kattan AF, and Lai Y (2013) Quantitative assessment of the contribution of sodium-dependent taurocholate co-transporting polypeptide (NTCP) to the hepatic uptake of rosuvastatin, pitavastatin and fluvastatin. Biopharm Drug Dispos 34:452-461.

Choi MK, Shin HJ, Choi YL, Deng JW, Shin JG, and Song IS (2011) Differential effect of genetic variants of $\mathrm{Na}(+)$-taurocholate co-transporting polypeptide (NTCP) and organic aniontransporting polypeptide 1B1 (OATP1B1) on the uptake of HMG-CoA reductase inhibitors. Xenobiotica 41:24-34.

Elsby R, Hilgendorf C, and Fenner K (2012) Understanding the critical disposition pathways of statins to assess drug-drug interaction risk during drug development: it's not just about OATP1B1. Clin Pharmacol Ther 92:584-598.

Giacomini KM, Huang SM, Tweedie DJ, Benet LZ, Brouwer KLR, Chu X, Dahlin A, Evers R, Fischer V, Hillgren KM, et al.; International Transporter Consortium (2010) Membrane transporters in drug development. Nat Rev Drug Discov 9:215-236.

Guo L, Dial S, Shi L, Branham W, Liu J, Fang JL, Green B, Deng H, Kaput J, and Ning B (2011) Similarities and differences in the expression of drug-metabolizing enzymes between human hepatic cell lines and primary human hepatocytes. Drug Metab Dispos 39:528-538.

Hagenbuch B and Gui C (2008) Xenobiotic transporters of the human organic anion transporting polypeptides (OATP) family. Xenobiotica 38:778-801.

Harwood MD, Achour B, Neuhoff S, Russell MR, Carlson G, Warhurst G, and Rostami-Hodjegan A (2016) In vitro-in vivo extrapolation scaling factors for intestinal P-glycoprotein and breast cancer resistance protein: part I: a cross-laboratory comparison of transporter-protein abundances and relative expression factors in human intestine and Caco-2 cells. Drug Metab Dispos 44:297-307.

Hirano M, Maeda K, Shitara Y, and Sugiyama Y (2004) Contribution of OATP2 (OATP1B1) and OATP8 (OATP1B3) to the hepatic uptake of pitavastatin in humans. J Pharmacol Exp Ther 311:139-146.

Ho RH, Tirona RG, Leake BF, Glaeser H, Lee W, Lemke CJ, Wang Y, and Kim RB (2006) Drug and bile acid transporters in rosuvastatin hepatic uptake: function, expression, and pharmacogenetics. Gastroenterology 130:1793-1806.

Huang HL, Hsing HW, Lai TC, Chen YW, Lee TR, Chan HT, Lyu PC, Wu CL, Lu YC, Lin ST, et al. (2010) Trypsin-induced proteome alteration during cell subculture in mammalian cells. $J$ Biomed Sci 17:36.

Ishiguro N, Maeda K, Kishimoto W, Saito A, Harada A, Ebner T, Roth W, Igarashi T, and Sugiyama Y (2006) Predominant contribution of OATP1B3 to the hepatic uptake of telmisartan, an angiotensin II receptor antagonist, in humans. Drug Metab Dispos 34:1109-1115.

Ji C, Tschantz WR, Pfeifer ND, Ullah M, and Sadagopan N (2012) Development of a multiplex UPLC-MRM MS method for quantification of human membrane transport proteins OATP1B1, OATP1B3 and OATP2B1 in in vitro systems and tissues. Anal Chim Acta 717:67-76.

Jigorel E, Le Vee M, Boursier-Neyret C, Bertrand M, and Fardel O (2005) Functional expression of sinusoidal drug transporters in primary human and rat hepatocytes. Drug Metab Dispos 33: $1418-1422$.

Jigorel E, Le Vee M, Boursier-Neyret C, Parmentier Y, and Fardel O (2006) Differential regulation of sinusoidal and canalicular hepatic drug transporter expression by xenobiotics activating drugsensing receptors in primary human hepatocytes. Drug Metab Dispos 34:1756-1763.

Jouan E, Le Vée M, Denizot C, Parmentier Y, and Fardel O (2016) Drug transporter expression and activity in human hepatoma HuH-7 cells. Pharmaceutics 9:3-14.

Kamiie J, Ohtsuki S, Iwase R, Ohmine K, Katsukura Y, Yanai K, Sekine Y, Uchida Y, Ito S, and Terasaki T (2008) Quantitative atlas of membrane transporter proteins: development and application of a highly sensitive simultaneous LC/MS/MS method combined with novel in-silico peptide selection criteria. Pharm Res 25:1469-1483.

Kimoto E, Chupka J, Xiao Y, Bi YA, and Duignan DB (2011) Characterization of digoxin uptake in sandwich-cultured human hepatocytes. Drug Metab Dispos 39:47-53.

Kimoto E, Yoshida K, Balogh LM, Bi YA, Maeda K, El-Kattan A, Sugiyama Y, and Lai Y (2012) Characterization of organic anion transporting polypeptide (OATP) expression and its functional contribution to the uptake of substrates in human hepatocytes. Mol Pharm 9:3535-3542.

Kitamura S, Maeda K, Wang Y, and Sugiyama Y (2008) Involvement of multiple transporters in the hepatobiliary transport of rosuvastatin. Drug Metab Dispos 36:2014-2023.

Kotani N, Maeda K, Debori Y, Camus S, Li R, Chesné C, and Sugiyama Y (2012) Expression and transport function of drug uptake transporters in differentiated HepaRG cells. Mol Pharm 9: $3434-3441$.

Kotani N, Maeda K, Watanabe T, Hiramatsu M, Gong LK, Bi YA, Takezawa T, Kusuhara H, and Sugiyama Y (2011) Culture period-dependent changes in the uptake of transporter substrates in sandwich-cultured rat and human hepatocytes. Drug Metab Dispos 39:1503-1510.

Kullak-Ublick GA, Ismair MG, Stieger B, Landmann L, Huber R, Pizzagalli F, Fattinger K, Meier PJ, and Hagenbuch B (2001) Organic anion-transporting polypeptide B (OATP-B) and its functional comparison with three other OATPs of human liver. Gastroenterology 120:525-533.

Kunze A, Huwyler J, Camenisch G, and Poller B (2014) Prediction of organic anion-transporting polypeptide 1B1- and 1B3-mediated hepatic uptake of statins based on transporter protein expression and activity data. Drug Metab Dispos 42:1514-1521.

Le Vee M, Jigorel E, Glaise D, Gripon P, Guguen-Guillouzo C, and Fardel O (2006) Functiona expression of sinusoidal and canalicular hepatic drug transporters in the differentiated human hepatoma HepaRG cell line. Eur J Pharm Sci 28:109-117. 
Le Vee M, Jouan E, Stieger B, Lecureur V, and Fardel O (2011) Regulation of drug transporter expression by oncostatin M in human hepatocytes. Biochem Pharmacol 82:304-311.

Le Vee M, Noel G, Jouan E, Stieger B, and Fardel O (2013) Polarized expression of drug transporters in differentiated human hepatoma HepaRG cells. Toxicol In Vitro 27:1979-1986.

Levy G, Bomze D, Heinz S, Ramachandran SD, Noerenberg A, Cohen M, Shibolet O, Sklan E, Braspenning J, and Nahmias Y (2015) Long-term culture and expansion of primary human hepatocytes. Nat Biotechnol 33:1264-1271.

Liu H and Sahi J (2016) Role of hepatic drug transporters in drug development. J Clin Pharmacol 56 (Suppl 7):S11-S22.

Masuda T, Saito N, Tomita M, and Ishihama Y (2009) Unbiased quantitation of Escherichia coli membrane proteome using phase transfer surfactants. Mol Cell Proteomics 8:2770-2777.

Masuda T, Tomita M, and Ishihama Y (2008) Phase transfer surfactant-aided trypsin digestion for membrane proteome analysis. J Proteome Res 7:731-740.

Ménochet K, Kenworthy KE, Houston JB, and Galetin A (2012) Use of mechanistic modeling to assess interindividual variability and interspecies differences in active uptake in human and rat hepatocytes. Drug Metab Dispos 40:1744-1756.

Nezasa K, Higaki K, Takeuchi M, Nakano M, and Koike M (2003) Uptake of rosuvastatin by isolated rat hepatocytes: comparison with pravastatin. Xenobiotica 33:379-388.

Ohtsuki S, Schaefer O, Kawakami H, Inoue T, Liehner S, Saito A, Ishiguro N, Kishimoto W, Ludwig-Schwellinger E, Ebner T, et al. (2012) Simultaneous absolute protein quantification of transporters, cytochromes P450, and UDP-glucuronosyltransferases as a novel approach for the characterization of individual human liver: comparison with mRNA levels and activities. Drug Metab Dispos 40:83-92.

Patel M, Taskar KS, and Zamek-Gliszczynski MJ (2016) Importance of hepatic transporters in clinical disposition of drugs and their metabolites. J Clin Pharmacol 56 (Suppl 7):S23-S39.

Peng KW, Bacon J, Zheng M, Guo Y, and Wang MZ (2015) Ethnic variability in the expression of hepatic drug transporters: absolute quantification by an optimized targeted quantitative proteomic approach. Drug Metab Dispos 43:1045-1055.

Ramachandran SD, Vivarès A, Klieber S, Hewitt NJ, Muenst B, Heinz S, Walles H, and Braspenning J (2015) Applicability of second-generation upcyte human hepatocytes for use in CYP inhibition and induction studies. Pharmacol Res Perspect 3:e0161.

Sakamoto A, Matsumaru T, Ishiguro N, Schaefer O, Ohtsuki S, Inoue T, Kawakami H, and Terasaki T (2011) Reliability and robustness of simultaneous absolute quantification of drug transporters, cytochrome P450 enzymes, and UDP-glucuronosyltransferases in human liver tissue by multiplexed MRM/selected reaction monitoring mode tandem mass spectrometry with nano-liquid chromatography. J Pharm Sci 100:4037-4043.

Schaefer M, Schänzle G, Bischoff D, and Süssmuth RD (2016) Upcyte human hepatocytes: potent in vitro tool for the prediction of hepatic clearance of metabolically stable compounds. Drug Metab Dispos 44:435-444.

Schaefer O, Ohtsuki S, Kawakami H, Inoue T, Liehner S, Saito A, Sakamoto A, Ishiguro N, Matsumaru T, Terasaki T, et al. (2012) Absolute quantification and differential expression of drug transporters, cytochrome P450 enzymes, and UDP-glucuronosyltransferases in cultured primary human hepatocytes. Drug Metab Dispos 40:93-103.
Stieger B and Hagenbuch B (2014) Organic anion-transporting polypeptides. Curr Top Membr 73 : 205-232.

Takikawa H (2002) Hepatobiliary transport of bile acids and organic anions. $J$ Hepatobiliary Pancreat Surg 9:443-447.

Tolosa L, Gómez-Lechón MJ, López S, Guzmán C, Castell JV, Donato MT, and Jover R (2016) Human upcyte hepatocytes: characterization of the hepatic phenotype and evaluation for acute and long-term hepatotoxicity routine testing. Toxicol Sci 152:214-229.

Trauner M and Boyer JL (2003) Bile salt transporters: molecular characterization, function, and regulation. Physiol Rev 83:633-671.

Uchida Y, Ohtsuki S, Katsukura Y, Ikeda C, Suzuki T, Kamiie J, and Terasaki T (2011) Quantitative targeted absolute proteomics of human blood-brain barrier transporters and receptors. $J$ Neurochem 117:333-345.

Uchida Y, Tachikawa M, Obuchi W, Hoshi Y, Tomioka Y, Ohtsuki S, and Terasaki T (2013) A study protocol for quantitative targeted absolute proteomics (QTAP) by LC-MS/MS: application for interstrain differences in protein expression levels of transporters, receptors, claudin-5, and marker proteins at the blood-brain barrier in ddY, FVB, and C57BL/6J mice. Fluids Barriers CNS 10:21.

Umehara KI, Iwatsubo T, Noguchi K, and Kamimura H (2007) Functional involvement of organic cation transporter1 (OCT1/Oct1) in the hepatic uptake of organic cations in humans and rats. Xenobiotica 37:818-831.

Vildhede A, Wiśniewski JR, Norén A, Karlgren M, and Artursson P (2015) Comparative proteomic analysis of human liver tissue and isolated hepatocytes with a focus on proteins determining drug exposure. J Proteome Res 14:3305-3314.

Webborn PJH, Parker AJ, Denton RL, and Riley RJ (2007) In vitro-in vivo extrapolation of hepatic clearance involving active uptake: theoretical and experimental aspects. Xenobiotica 37: $1090-1109$.

Wegler C, Gaugaz FZ, Andersson TB, Wiśniewski JR, Busch D, Gröer C, Oswald S, Norén A Weiss F, Hammer HS, et al. (2017) Variability in mass spectrometry-based quantification of clinically relevant drug transporters and drug metabolizing enzymes. Mol Pharm 14: 3142-3151.

Yang Q, Doshi U, Li N, and Li AP (2012) Effects of culture duration on gene expression of P450 isoforms, uptake and efflux transporters in primary hepatocytes cultured in the absence and presence of interleukin-6: implications for experimental design for the evaluation of downregulatory effects of biotherapeutics. Curr Drug Metab 13:938-946.

Yoshida K, Maeda K, and Sugiyama Y (2013) Hepatic and intestinal drug transporters: prediction of pharmacokinetic effects caused by drug-drug interactions and genetic polymorphisms. Annu Rev Pharmacol Toxicol 53:581-612.

Address correspondence to: Michelle Schaefer, Department of Quantitative Pharmacology and Disposition, Merck KGaA, Frankfurter St. 250, 64293 Darmstadt, Germany. E-mail: michelle.schaefer@merckgroup.com 